\title{
Radiative Effects of Clouds and Water Vapor on an Axisymmetric Monsoon
}

\author{
MiCHAEL P. BYRNE \\ University of St. Andrews, St. Andrews, and University of Oxford, Oxford, United Kingdom \\ LAURE ZANNA \\ Courant Institute of Mathematical Sciences, New York University, New York City, New York, and University of Oxford, \\ Oxford, United Kingdom
}

(Manuscript received 22 December 2019, in final form 20 July 2020)

\begin{abstract}
Monsoons are summertime circulations shaping climates and societies across the tropics and subtropics. Here the radiative effects controlling an axisymmetric monsoon and its response to climate change are investigated using aquaplanet simulations. The influences of clouds, water vapor, and $\mathrm{CO}_{2}$ on the axisymmetric monsoon are decomposed using the radiation-locking technique. Seasonal variations in clouds and water vapor strongly modulate the axisymmetric monsoon, reducing net precipitation by approximately half. Warming and moistening of the axisymmetric monsoon by seasonal longwave cloud and water vapor effects are counteracted by a strong shortwave cloud effect. The shortwave cloud effect also expedites onset of the axisymmetric monsoon by approximately two weeks, whereas longwave cloud and water vapor effects delay onset. A conceptual model relates the timing of monsoon onset to the efficiency of surface cooling. In climate change simulations $\mathrm{CO}_{2}$ forcing and the water vapor feedback have similar influences on the axisymmetric monsoon, warming the surface and moistening the region. In contrast, clouds have a negligible effect on surface temperature yet dominate the monsoon circulation response. A new perspective for understanding how cloud radiative effects shape the monsoon circulation response to climate change is introduced. The radiation-locking simulations and analyses advance understanding of how radiative processes influence an axisymmetric monsoon, and establish a framework for interpreting monsoon-radiation coupling in observations, in state-of-the-art models, and in different climate states.
\end{abstract}

KEYWORDS: Large-scale motions; Monsoons; Climate change; Cloud radiative effects; Radiative fluxes; Water vapor

\section{Introduction}

Monsoons are large-scale summertime circulations providing rainfall to more than half the global population. Monsoons are vital for agriculture and societies in Asia, Africa, Australia, and the Americas, and are expected to change dramatically in future decades due to global warming (Turner and Annamalai 2012). However, monsoon predictions from state-of-the-art climate models are highly uncertain (e.g., Wang et al. 2020) and this uncertainty has persisted despite huge effort and cost in developing higher-resolution models with greater complexity. Constructing more complex climate models will not by itself resolve the large

Corresponding author: Michael P. Byrne, mpb20@st-andrews. ac.uk uncertainty in monsoon predictions; improved understanding of the processes and mechanisms controlling monsoons and their response to climate change is also needed.

Here idealized aquaplanet simulations are used to investigate a question that has received little attention: How do radiative processes influence monsoons and their responses to climate change? The impacts of aerosols on monsoons are well studied, with suggestions that anthropogenic aerosols may weaken and dry the South and East Asian monsoons (Bollasina et al. 2011; Dong et al. 2019). But aside from aerosols, the extent to which the radiative effects of $\mathrm{CO}_{2}$, clouds, and water vapor are important for monsoons is unclear. In this study the radiation-locking method is used to isolate the effects of $\mathrm{CO}_{2}$ forcing and "moist-radiative feedbacks" associated with clouds and water vapor (Bony and 
Emanuel 2005) on an axisymmetric monsoon. Moistradiative feedbacks are fundamental to tropical intraseasonal dynamics (e.g., Bony and Emanuel 2005) and convective self-aggregation (Wing and Emanuel 2014), yet their implications for monsoons have not been thoroughly investigated.

Radiative forcings and feedbacks are typically discussed in the context of global surface temperature and its response to climate change (e.g., Andrews et al. 2012). Yet spatial variations in forcings and feedbacks imprint upon the top-of-atmosphere (TOA) energy balance, affecting heat transport and the atmospheric circulation (Zelinka and Hartmann 2012; Merlis 2015; Roe et al. 2015). Studies using the radiation-locking method have shown how cloud and water vapor feedbacks shape the responses of the intertropical convergence zone (ITCZ), storm tracks, and Hadley cells to climate change (Zhang et al. 2010; Voigt and Shaw 2015; Ceppi and Hartmann 2016; Clark et al. 2018), have highlighted the role of clouds in controlling hemispheric albedo asymmetries (Voigt et al. 2014), and have estimated the contribution of the water vapor feedback to climate sensitivity (Hall and Manabe 1999). However, the radiation-locking method has not been applied to understand the roles of clouds, water vapor, and $\mathrm{CO}_{2}$ in controlling the monsoon response to climate change. It is important to assess whether the substantial uncertainties in cloud feedbacks across climate models (e.g., Bony et al. 2011) have the potential to explain a portion of the large intermodel spread in monsoon projections (Kitoh et al. 2013). Perhaps more fundamentally, the extent to which monsoons in the present climate are influenced by moistradiative feedbacks remains an open question. Ackerman and Cox (1987) observed differences of approximately $100 \mathrm{~W} \mathrm{~m}^{-2}$ in atmospheric radiative heating between clear and cloudy monsoon regions, and simulations show a substantial influence of this cloud radiative effect on the East Asian monsoon circulation (Guo et al. 2015). These studies suggest that seasonal cloud radiative effects play an important role in energizing monsoons and could, in addition to water vapor effects, contribute to mean-state monsoon biases in climate models (e.g., Seth et al. 2013).

We begin by describing the radiation-locking simulations (section 2) before analyzing the radiative effects controlling an axisymmetric version of the climatological monsoon (section 3) and its response to an abrupt increase in $\mathrm{CO}_{2}$ (section 4). The effects of clouds and water vapor on the climatological axisymmetric monsoon and its response to climate change are compared (section 5) before we conclude with a summary of key results (section 6).

\section{Radiation-locking simulations}

To explore the radiative effects of clouds, water vapor, and $\mathrm{CO}_{2}$ on monsoons, simulations are performed using the Community Atmosphere Model version 4.0 (CAM4) (Neale et al. 2010), an atmospheric component of the Community Earth System Model (CESM; Hurrell et al. 2013) version 1.2.2. The model is configured as an axisymmetric, slab-ocean aquaplanet with a mixed-layer depth of $5 \mathrm{~m}$ and no horizontal heat transfer within the slab (i.e., zero $q$-flux at every grid point). The setup is axisymmetric in the sense that the boundary conditions are zonally symmetric (e.g., Bordoni and Schneider 2008), not axisymmetric in the sense that the simulations are 2D (e.g., Privé and Plumb 2007). The mixed-layer depth is chosen so as to capture key monsoon features including abrupt onset, and to obtain seasonal cycles of subtropical zonal wind and precipitation that are qualitatively similar to observations. Note that the climates of aquaplanets depend on mixedlayer depth (Donohoe et al. 2014; Wei and Bordoni 2018). The axisymmetric monsoon discussed below is also likely to be sensitive to mixed-layer depth but this dependence is not explored here. All simulations have a seasonal cycle of insolation with a solar constant equal to $1365 \mathrm{~W} \mathrm{~m}^{-2}$, an obliquity of $23.5^{\circ}$, zero orbital eccentricity, and no aerosols. The nominal horizontal grid spacing is $2^{\circ}$ and there are 26 vertical levels. Simulations are run for 60 years and climatological monthly averages are taken over the final 40 years. Climatological monthlyaverage July data are used to define the axisymmetric monsoon, although daily data are used when investigating monsoon onset in section 3 .

\section{a. On the use of an axisymmetric model}

Although observed monsoons have strong zonal asymmetries, the essential dynamics of monsoons - including abrupt onset and seasonal wind reversal-are captured by axisymmetric models (e.g., Yano and McBride 1998; Chao 2000; Bordoni and Schneider 2008; Schneider and Bordoni 2008; Geen et al. 2019). This simplified framework has frequently been used to explore the fundamental physical mechanisms controlling monsoons (Privé and Plumb 2007) and the tropical atmospheric circulation more generally (e.g., Schneider 1977; Held and Hou 1980; Lindzen and Hou 1988; Plumb and Hou 1992). The objective here is to build on previous axisymmetric studies and take a first step toward understanding the radiative effects of clouds, water vapor, and $\mathrm{CO}_{2}$ on monsoons. While an idealized approach is justified given the paucity of previous research on monsoon-radiation coupling, the simplifications involved may limit the applicability of the results. In 


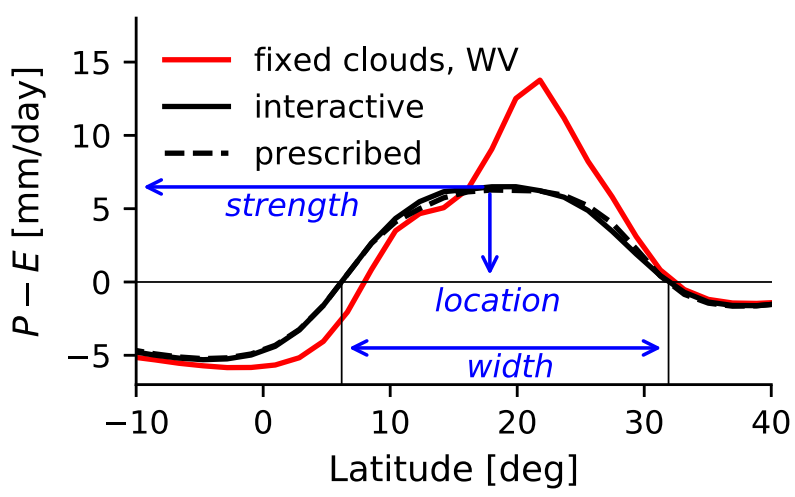

FIG. 1. Precipitation minus evaporation in the axisymmetric monsoon region for the control simulation with fully interactive radiation $\left(1 \times \mathrm{CO}_{2}\right.$; solid black line $)$, for the simulation with prescribed seasonally varying clouds and water vapor profiles in the radiation code $\left(\mathrm{S}_{\mathrm{var}} \mathrm{L}_{\mathrm{var}} \mathrm{W}_{\mathrm{var}}\right.$; dashed black line) and for the simulation in which clouds and water vapor are fixed to their annualmean profiles in the radiation code $\left(\mathrm{S}_{\mathrm{fix}} \mathrm{L}_{\mathrm{fix}} \mathrm{W}_{\mathrm{fix}}\right.$; solid red line). The blue arrows and text indicate the location, width, and strength of the axisymmetric monsoon in the control simulation. The monsoon structure is defined using climatological monthly average July data.

particular, the effects of moist-radiative feedbacks and $\mathrm{CO}_{2}$ forcing on axisymmetric versus realistic monsoons may differ due to a range of processes being neglected in the aquaplanet framework. Potentially important processes not considered in this study include surface hydrology and moisture and energy transports by the zonally asymmetric component of the monsoon flow (e.g., Shaw and Voigt 2016)—which likely impact, for example, the observed spatial patterns of cloud and water vapor feedbacks ( $\mathrm{Li}$ et al. 2017) - and the mechanical and thermodynamic influences of orography (e.g., Molnar et al. 2010). An aim of this study is to motivate future research investigating the impacts of such processes on monsoon-radiation coupling, with the goal of developing a comprehensive understanding of these interactions that is applicable to observed monsoons and to full-complexity models.

\section{b. Definition of the axisymmetric monsoon structure}

While acknowledging that monsoons are characterized using a variety of metrics and variables (e.g., Wang and Ding 2008), here the spatial structure of the axisymmetric monsoon is defined in terms of precipitation minus evaporation $(P-E)$. The use of $P-E$ allows for an unambiguous definition of monsoon boundary latitudes (where $P-E=0$; Fig. 1) and enables a straightforward, physically insightful decomposition of monsoon responses into dynamic and thermodynamic terms (Seager et al. 2010). The axisymmetric monsoon structure is defined by three metrics: width, location, and strength. The width of the monsoon is specified as the degrees of latitude between the northern and southern monsoon edges (Fig. 1). The monsoon edges are defined as the latitudes closest to the equator in the Northern Hemisphere at which July-mean $P-E=0$. This definition of axisymmetric monsoon width in terms of the zero-crossing latitudes of $P-E$ is analogous to definitions of the widths of the Hadley cells (Lu et al. 2007) and ITCZ (Byrne and Schneider 2016). The location of the axisymmetric monsoon $\phi_{M}$ is defined as the latitude of maximum July-mean $P-E$ within the region enclosed by the monsoon edges (Fig. 1). Using a similar technique to Adam et al. (2016) [see their Eq. (1a)], the monsoon location is identified by weighting latitude to a high integer power of $P-E$ :

$$
\phi_{M}=\frac{\int_{\phi_{s}}^{\phi_{n}} \phi[\cos \phi \times(P-E)]^{N} d \phi}{\int_{\phi_{s}}^{\phi_{n}}[\cos \phi \times(P-E)]^{N} d \phi},
$$

where $\phi_{s}$ and $\phi_{n}$ are the southern and northern edges of the axisymmetric monsoon, respectively, and $N=10$. This integral method is used to find the axisymmetric monsoon location so as to reduce discretization noise that would affect finding the latitude of maximum $P-E$ directly (Adam et al. 2016). The strength of the axisymmetric monsoon is defined as the value of $P-E$ at the monsoon location (Fig. 1). Note that the specific results presented in this paper are likely to depend on the choice of axisymmetric monsoon structure outlined above.

\section{c. Seasonal cycle simulations}

Radiation-locking simulations aimed at understanding how seasonal cloud and water vapor effects shape a climatological, axisymmetric monsoon are performed. Using these simulations, the contributions of moistradiative feedbacks (clouds, water vapor) to controlling the axisymmetric monsoon are quantified. In particular, three contributions due to 1) water vapor, 2) longwave (LW) cloud effects, and 3) shortwave (SW) cloud effects are decomposed. These influences of clouds and water vapor on the axisymmetric monsoon are quantified by running a suite of eight simulations in which clouds (SW and LW properties separately) and water vapor in the model's radiation code are "locked" to either annual-mean or seasonally varying profiles so as to either disable or enable insolation-induced feedbacks. The radiation-locking simulations all have identical insolation and a $\mathrm{CO}_{2}$ concentration of 284.7 ppmv. The cloud and water vapor profiles prescribed in the radiation-locking simulations are taken from a control run with fully interactive, seasonally varying radiation. 
TABLE 1. Radiation-locking simulations to decompose the influences of clouds and water vapor on a climatological, axisymmetric monsoon. Here "S" stands for SW cloud properties, "L" for LW cloud properties, and "W" for water vapor. The subscript "fix" indicates that the property in question is fixed to its annual-mean profile from the control simulation in the model's radiation code, and "var" denotes a seasonally varying cloud or water vapor profile.

\begin{tabular}{c}
\hline Seasonal cycle simulations \\
\hline $\mathrm{S}_{\text {fix }} \mathrm{L}_{\text {fix }} \mathrm{W}_{\text {fix }}$ \\
$\mathrm{S}_{\text {fix }} \mathrm{L}_{\text {fix }} \mathrm{W}_{\text {var }}$ \\
$\mathrm{S}_{\text {fix }} \mathrm{L}_{\mathrm{var}} \mathrm{W}_{\text {fix }}$ \\
$\mathrm{S}_{\text {fix }} \mathrm{L}_{\mathrm{var}} \mathrm{W}_{\mathrm{var}}$ \\
$\mathrm{S}_{\mathrm{var}} \mathrm{L}_{\mathrm{fix}} \mathrm{W}_{\text {fix }}$ \\
$\mathrm{S}_{\mathrm{var}} \mathrm{L}_{\mathrm{fix}} \mathrm{W}_{\mathrm{var}}$ \\
$\mathrm{S}_{\mathrm{var}} \mathrm{L}_{\mathrm{var}} \mathrm{W}_{\text {fix }}$ \\
$\mathrm{S}_{\mathrm{var}} \mathrm{L}_{\mathrm{var}} \mathrm{W}_{\mathrm{var}}$ \\
\hline
\end{tabular}

In this control simulation (named " $1 \times \mathrm{CO}_{2}$ "), the cloud and water vapor fields are stored every $2 \mathrm{~h}$ in preparation for being prescribed (also every $2 \mathrm{~h}$ ) in the subsequent radiation-locking simulations, which are listed in Table 1.

By comparing differences in the axisymmetric monsoon between simulations with and without seasonally varying clouds and/or water vapor, the effects of seasonal cloud and water vapor feedbacks on the monsoon can be decomposed. ${ }^{1}$ The decomposition is constructed such that the sum of the effects of clouds and water vapor on any given variable (plus a residual due to nonlinear interactions between clouds and water vapor) is equal to the change in that variable between the simulation with seasonally varying clouds and water vapor $\left(\mathrm{S}_{\mathrm{var}} \mathrm{L}_{\mathrm{var}} \mathrm{W}_{\mathrm{var}}\right.$; see Table 1$)$ and the simulation with clouds and water vapor locked to their annual-mean profiles $\left(\mathrm{S}_{\mathrm{fix}} \mathrm{L}_{\mathrm{fix}} \mathrm{W}_{\text {fix }}\right)$. See the appendix for a complete description of the decomposition. Ceppi and Hartmann (2016) used a similar method to decompose the annualmean circulation response to $\mathrm{CO}_{2}$ forcing but to our knowledge this is the first study to apply the radiationlocking method to investigate an axisymmetric monsoon. The simulations are designed to provide answers to a number of unresolved questions: Do the radiative effects of clouds and water vapor strengthen or weaken the axisymmetric monsoon? Are these effects driven by dynamic or thermodynamic processes? How do moist-radiative feedbacks associated with clouds and water vapor affect the pace of onset of an axisymmetric monsoon?

\footnotetext{
${ }^{1}$ An alternative approach to decomposing seasonal moistradiative effects on the monsoon would be to allow the seasonally varying clouds and water vapor to evolve freely, rather than locking them in the radiation code. The extent to which simulations using this alternative method would modify the results presented here is a topic for future work.
}

Radiation locking is useful for this problem only if the fully interactive control simulation $\left(1 \times \mathrm{CO}_{2}\right)$ and the locked simulation with prescribed seasonally varying clouds and water $\left(\mathrm{S}_{\mathrm{var}} \mathrm{L}_{\mathrm{var}} \mathrm{W}_{\mathrm{var}}\right)$ produce similar axisymmetric monsoons. So long as this condition is satisfied, the climatological monsoon can be expressed approximately as a linear sum of the insolation-only, cloud, and water vapor components. That the radiation-locking method should work for the monsoon is not guaranteed: nonlinear interactions between clouds, water vapor, and radiation could lead to substantial differences between the interactive and locked simulations. To test the validity of the radiation-locking method, the axisymmetric monsoons in the fully interactive control simulation and in the locked simulation are compared (Fig. 1). Prescribing seasonally varying cloud and water vapor fields produces an axisymmetric monsoon that, in terms of $P-E$, is almost identical to the fully interactive control simulation (Fig. 1). This confirms that nonlinear interactions between insolation, clouds, and water vapor over the seasonal cycle are negligible, and that the radiation-locking method is a useful tool for decomposing how each process controls the climatological, axisymmetric monsoon.

\section{d. Climate change simulations}

An additional suite of simulations is performed to decompose how $\mathrm{CO}_{2}$ radiative forcing and feedbacks due to clouds and water vapor control the axisymmetric monsoon response to an abrupt quadrupling of the atmospheric $\mathrm{CO}_{2}$ concentration. Control $\left(1 \times \mathrm{CO}_{2}\right)$ and perturbed $\left(4 \times \mathrm{CO}_{2}\right)$ simulations with fully interactive radiation are first performed to generate the cloud and water vapor data for the radiation-locking simulations. The control and perturbed simulations have $\mathrm{CO}_{2}$ concentrations of 284.7 and 1138.8 ppmv, respectively.

The total response of the axisymmetric monsoon to $\mathrm{CO}_{2}$ quadrupling is decomposed into four contributions: 1) $\mathrm{CO}_{2}$ forcing, 2) water vapor feedback, 3) LW cloud feedback, and 4) SW cloud feedback. The decomposition of the total response is achieved by running 16 additional simulations in which $\mathrm{CO}_{2}$, water vapor, and clouds are locked to their time-varying values from either the control or perturbed simulation. The 16 locking simulations are listed in Table 2. As for the seasonal cycle simulations discussed in section $2 \mathrm{c}$, the $\mathrm{CO}_{2}$ forcing, and cloud/water vapor components of the total change in the monsoon are estimated by taking differences between pairs of the locked simulations; see the appendix for a full description of how each component is calculated.

The utility of the radiation-locking method for understanding the axisymmetric monsoon response to climate change is assessed by comparing changes in various 
TABLE 2. Simulations to decompose radiative influences on the axisymmetric monsoon response to climate change. Here "C" stands for the $\mathrm{CO}_{2}$ concentration, "S" for SW cloud properties, "L" for LW cloud properties, and "W" for water vapor; " 1 " indicates that the property in question is locked in the model's radiation code to its values in the control simulation $\left(1 \times \mathrm{CO}_{2}\right)$, and " 4 " indicates that values are prescribed from the perturbed simulation $\left(4 \times \mathrm{CO}_{2}\right)$.

\begin{tabular}{ll}
\hline \hline \multicolumn{2}{c}{ Climate change simulations } \\
\hline C1S1L1W1 & C4S1L1W1 \\
C1S1L1W4 & C4S1L1W4 \\
C1S1L4W1 & C4S1L4W1 \\
C1S1L4W4 & C4S1L4W4 \\
C1S4L1W1 & C4S4L1W1 \\
C1S4L1W4 & C4S4L1W4 \\
C1S4L4W1 & C4S4L4W1 \\
C1S4L4W4 & C4S4L4W4 \\
\hline
\end{tabular}

quantities in the monsoon region between 1) the fully interactive control and perturbed simulations $\left(4 \times \mathrm{CO}_{2}\right.$ minus $1 \times \mathrm{CO}_{2}$ ) and 2) the control and perturbed simulations with locked clouds and water vapor (i.e., between the C4S4L4W4 and C1S1L1W1 simulations; see Table 2). Overall the method performs well for changes in sea surface temperature (SST), $P-E$, air temperature, and mass streamfunction in the monsoon region, with generally small differences between the locked and fully interactive simulations (Fig. 2). Thus, radiation locking is an appropriate tool for investigating axisymmetric monsoon responses to climate change.

\section{Radiative effects on an axisymmetric monsoon: Seasonal cycle}

Using the radiation-locking method, the processes controlling the climatological, axisymmetric monsoon are decomposed into contributions from seasonally varying insolation and the induced water vapor and cloud responses. Seasonally varying clouds and water vapor exert a large influence on the climatological, axisymmetric monsoon (Fig. 1). Compared to a simulation in which clouds and water vapor are locked to their annual-mean profiles, permitting these atmospheric constituents to migrate with the seasonal cycle of insolation reduces the maximum in axisymmetric monsoon $P-E$ by approximately half. The SW radiative effect of clouds is the dominant influence on the axisymmetric monsoon (aside from insolation itself), drying the core of the monsoon region by approximately $5 \mathrm{~mm}$ day $^{-1}$ and moistening the margins (Fig. 3). The SW cloud effect tends to shift the location of the axisymmetric monsoon poleward by approximately $1^{\circ}$ (Fig. 4a). More dramatically, the pattern of drying and moistening induced by the SW cloud effect widens the axisymmetric monsoon region by more than $6^{\circ}$ (Fig. 4b) but dries maximum monsoon $P-E$ by more than $30 \%$ (Fig. 4c). The seasonal water vapor and LW cloud effects partially counteract the poleward shift and widening of the monsoon induced by the SW cloud effect (Figs. 4a,b). The water vapor and LW cloud components have comparable meridional structures, tending to moisten the monsoon core and dry the margins (Fig. 3). The SW and LW influences of clouds cancel each other to a large extent (Figs. 3 and $4 \mathrm{a}-\mathrm{c}$ ), which is consistent with the SW and LW cloud radiative effects approximately balancing one another in the tropics (e.g., Ramanathan et al. 1989). The residual term representing nonlinear interactions between clouds and water vapor contributes to drying in the core of the monsoon region and moistening on the flanks, and is the smallest component of the total response (Fig. 3).

Water vapor feedbacks have been shown to shift the annual-mean ITCZ poleward by creating a hemispheric asymmetry in TOA energy fluxes (Frierson and Hwang 2012; Clark et al. 2018). A TOA energy imbalance between hemispheres perturbs the cross-equatorial energy flux which, according to energy flux equator theory (e.g., Kang et al. 2008), shifts the ITCZ location. A poleward shift of the annual-mean ITCZ due to water vapor apparently contradicts the weak equatorward shift of the axisymmetric monsoon shown in Fig. 4a. However, energy flux equator theory does not accurately describe ITCZ migrations on subseasonal time scales (Wei and Bordoni 2018), suggesting that arguments for how water vapor affects the annualmean ITCZ are not appropriate for explaining the influence on the axisymmetric monsoon. A theory based on convective quasi-equilibrium relates monsoon locations to near-surface moist static energy (Privé and Plumb 2007; Nie et al. 2010), and could be invoked to examine the shifts in axisymmetric monsoon location due to clouds and water vapor.

The decomposition of the climatological, axisymmetric monsoon into contributions from moistradiative processes highlights how clouds and water vapor are fundamental to the axisymmetric monsoon; in the absence of seasonally varying clouds and water vapor the axisymmetric monsoon would be substantially stronger and peak farther poleward (Fig. 1). Below, the mechanisms by which clouds and water vapor impact the monsoon are investigated.

\section{a. Atmospheric moisture budget decomposition}

The atmospheric moisture budget is analyzed to understand and compare the processes by which the 

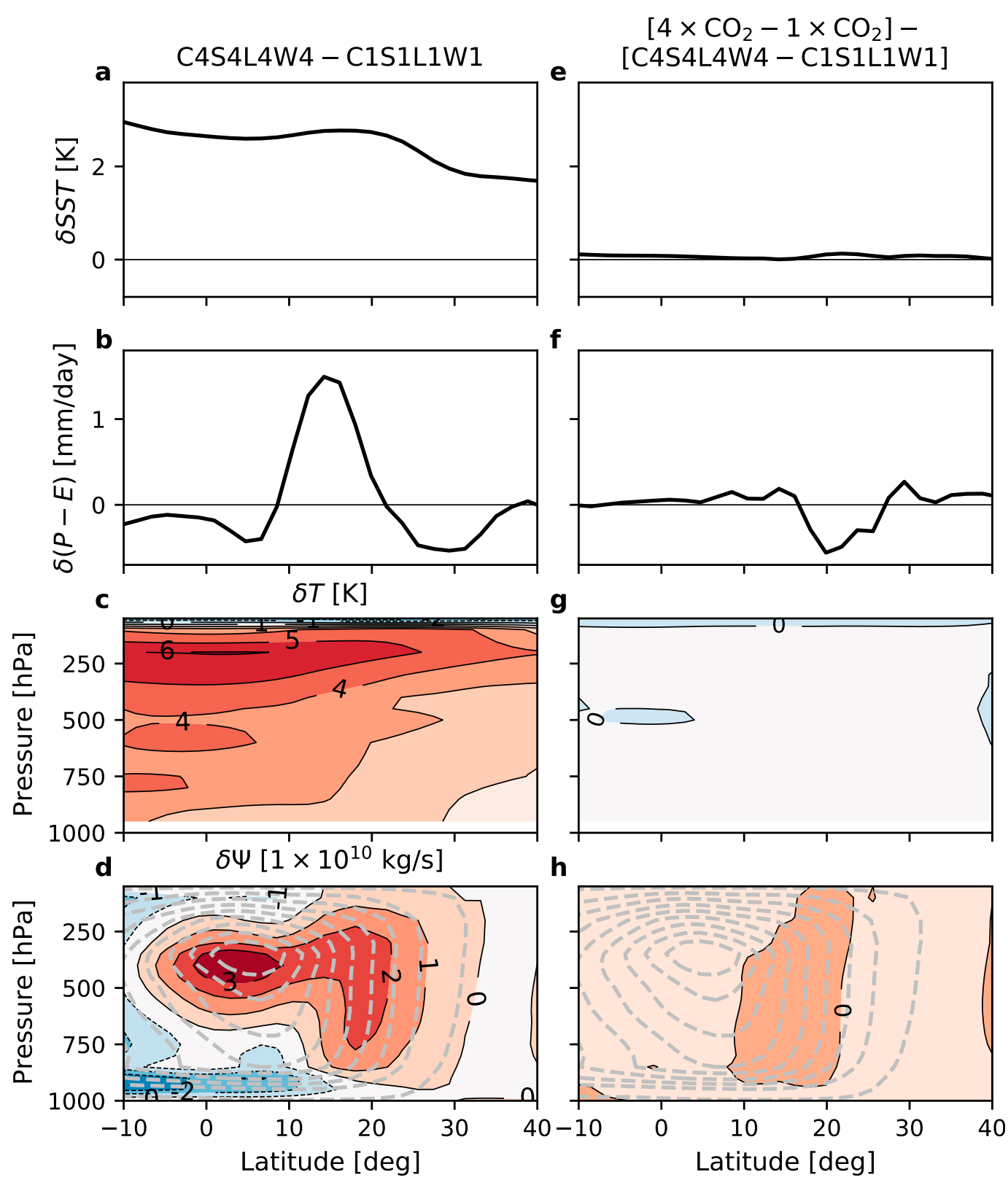

FIG. 2. Changes in July zonal mean (a) sea surface temperature, (b) precipitation minus evaporation, (c) air temperature, and (d) mass streamfunction between the locked climate change simulations (C4S4L4W4 minus C1S1L1W1). (e)-(h) Differences in the changes in each variable between the fully interactive perturbed and control simulations $\left(4 \times \mathrm{CO}_{2}\right.$ minus $\left.1 \times \mathrm{CO}_{2}\right)$ and the locked simulations (C4S4L4W4 minus C1S1L1W1). For the streamfunction panels $[(\mathrm{d})$ and $(\mathrm{h})]$, colors indicate the changes and the dashed gray contours show the axisymmetric monsoon overturning circulation in the control simulation $\left(1 \times \mathrm{CO}_{2}\right)$.

radiative effects of water vapor and clouds (and later $\mathrm{CO}_{2}$ forcing) influence the axisymmetric monsoon. Specifically, changes in zonal-mean $P-E$ are decomposed into mean thermodynamic, mean dynamic, transient eddy, and nonlinear terms following Seager et al. (2010):

$$
\begin{aligned}
\delta(P-E)= & \underbrace{-\nabla \cdot[\bar{v} \delta(\bar{q})]}_{\delta \mathrm{MTh}} \underbrace{-\nabla \cdot[\delta(\bar{v}) \bar{q}]}_{\delta \mathrm{MDyn}} \\
& \underbrace{-\nabla \cdot \delta\left(\left[\bar{v}^{\prime} q^{\prime}\right]\right)}_{\delta \mathrm{Eddy}} \underbrace{-\nabla \cdot[\delta(\bar{v}) \delta(\bar{q})]}_{\delta \mathrm{NL}},
\end{aligned}
$$




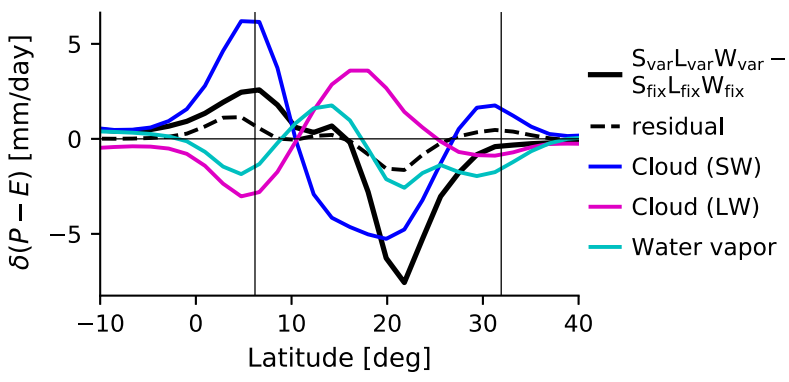

FIG. 3. Difference in precipitation minus evaporation (solid black line) between the simulation with seasonally varying clouds and water vapor and the simulation with cloud and water vapor profiles locked to their annual-mean profiles (i.e., $\mathrm{S}_{\mathrm{var}} \mathrm{L}_{\mathrm{var}} \mathrm{W}_{\mathrm{var}}$ minus $\mathrm{S}_{\text {fix }} \mathrm{L}_{\mathrm{fix}} \mathrm{W}_{\text {fix }}$ ). The $\mathrm{SW}$ cloud (blue line), LW cloud (magenta line), and water vapor (cyan line) components of the $P-E$ response are also shown. The dashed black line shows the residual term representing the effect of nonlinear interactions between clouds and water vapor (see appendix). Here and in subsequent figures the thin vertical black lines indicate the edges of the axisymmetric monsoon region.

where $v$ is the meridional wind, $q$ is the specific humidity, $[\cdot] \equiv(1 / g) \int_{0}^{p_{s}}(\cdot) d p$ represents a mass-weighted vertical integral through the atmosphere ( $g$ is the gravitational acceleration and $p_{s}$ is the surface pressure), overbars $\overline{(\cdot)}$ indicate climatological monthly means, and primes $(\cdot)^{\prime}$ represent departures from monthly means. The mean thermodynamic component $(\delta \mathrm{MTh})$ represents the influence of changes in specific humidity on $P-E$ with fixed winds, and the mean dynamic component ( $\delta$ MDyn) is the change in atmospheric moisture convergence due to a change in mean winds with fixed specific humidity. Note that monthly-mean circulation responses induced by SST warming or cooling patterns will be included in the mean dynamic component, despite being driven by temperature changes. The transient eddy component ( $\delta$ Eddy) is a covariance term associated with correlations in submonthly winds and specific humidity. The nonlinear term $(\delta N L)$ represents the combined effect on $P-E$ of changes in mean circulation and mean specific humidity. The mean dynamic term can be further decomposed into divergent and advective components:

$$
\delta \text { MDyn }=-\nabla \cdot[\delta(\bar{v}) \bar{q}] \approx \underbrace{-[(\nabla \cdot \delta \bar{v}) \bar{q}]}_{\text {div. }} \underbrace{-[\delta \bar{v} \cdot \nabla \bar{q}]}_{\text {adv. }} .
$$

The approximation in (3) arises from Leibniz's integral rule, which implies that there should be an additional term on the right-hand side related to moisture advection down surface pressure gradients. However, this surface term is generally small and often neglected when investigating changes in $P-E$ (e.g., Seager et al. 2010); it is not discussed further here.

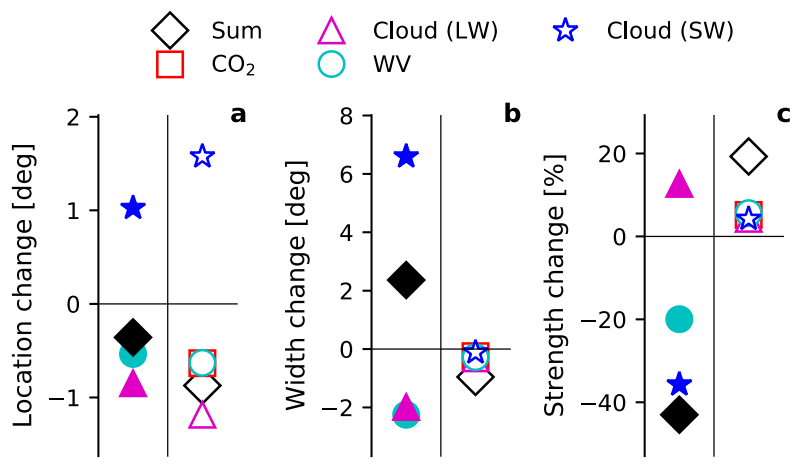

FIG. 4. Changes in (a) location, (b) width, and (c) strength of the axisymmetric monsoon when seasonally varying water vapor and cloud effects are active (filled symbols) and in response to a quadrupling of $\mathrm{CO}_{2}$ (unfilled symbols). Red squares show the changes due to $\mathrm{CO}_{2}$ forcing alone, cyan circles show the changes due to water vapor, the blue stars and magenta triangles show the changes associated with SW and LW cloud effects, respectively, and the black diamonds show the sums of all components for each metric. The axisymmetric monsoon metrics are defined in terms of $P-E$ (see section $2 \mathrm{~b}$ ) and are discussed in detail at the beginning of section 3 . The simulation data used to compute the changes associated with $\mathrm{CO}_{2}$, water vapor, and clouds are described in detail in the appendix.

\section{b. Dynamic versus thermodynamic effects on the climatological, axisymmetric monsoon}

Clouds and water vapor primarily influence the climatological, axisymmetric monsoon through the mean dynamic term (2) by modifying the circulation (Fig. 5a). The radiative effects of water vapor and clouds (LW) broadly moisten the core of the axisymmetric monsoon region by strengthening the divergent flow and enhancing ascent (Figs. 5b,c); there is little influence from the mean thermodynamic, transient eddy, or nonlinear terms. Water vapor, in addition, induces a substantial weakening of the divergent circulation with an associated drying centered at approximately $20^{\circ} \mathrm{N}$. As for the water vapor and LW cloud components, the SW influence of clouds is primarily associated with changes in the mean divergent circulation, which dry the axisymmetric monsoon core and moisten the flanks (Fig. 5d). But the SW cloud effect also exerts a substantial thermodynamic influence on the axisymmetric monsoon by contributing to a large negative TOA anomaly during the monsoon season (Fig. 6a) that strongly cools the region (Fig. 7a).

The influence of the SW cloud effect on the climatological, axisymmetric monsoon is straightforward to understand in physical terms: Clouds reflect SW radiation and reduce net TOA incoming radiation (Fig. 6a), which dries the core of the axisymmetric monsoon through a combination of cooling (thermodynamic) and weakening of the thermally driven circulation (dynamic). On the other hand, seasonally varying water 


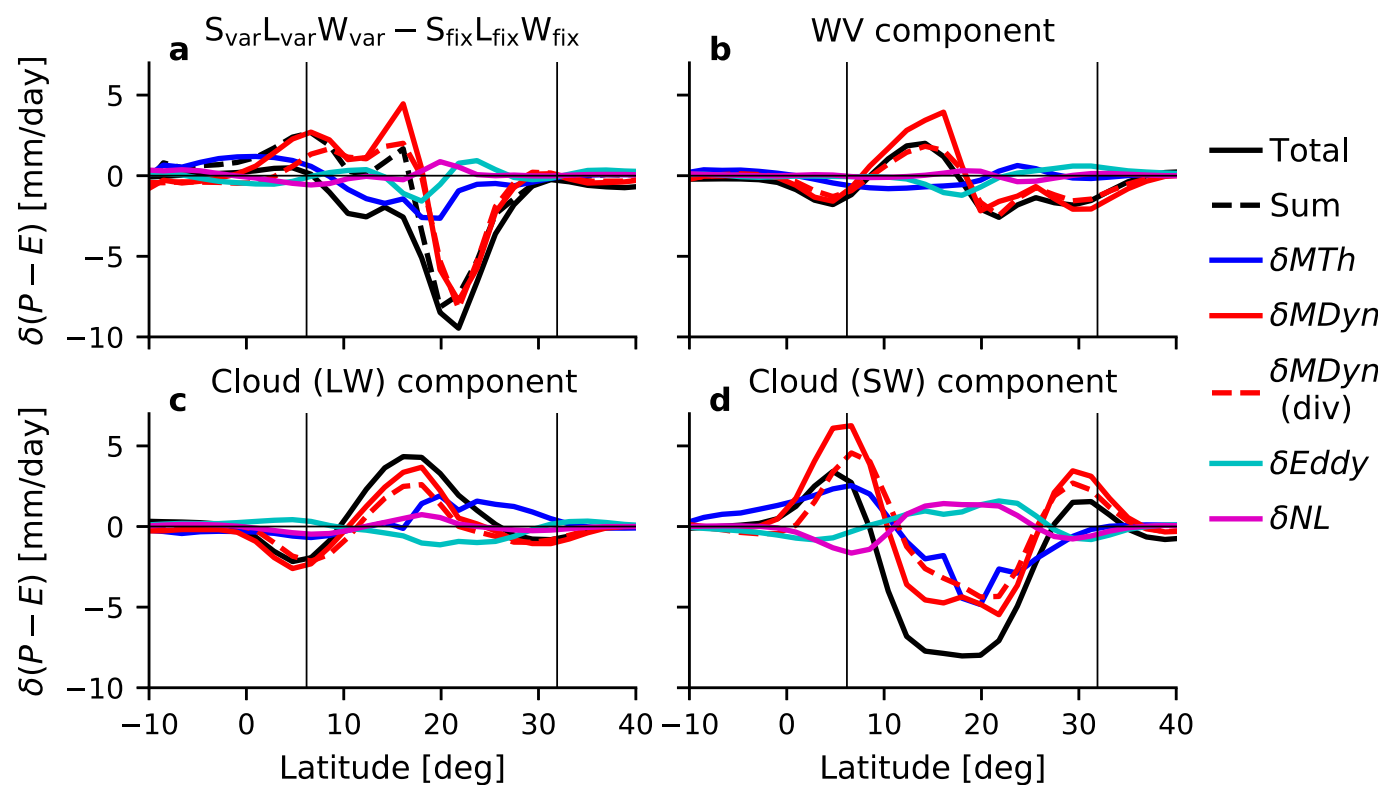

FIG. 5. (a) Difference in precipitation minus evaporation between the simulation with seasonally varying cloud and water vapor profiles and the simulation with annual-mean cloud and water vapor profiles $\left(\mathrm{S}_{\mathrm{var}} \mathrm{L}_{\mathrm{var}} \mathrm{W}_{\mathrm{var}}\right.$ minus $\mathrm{S}_{\text {fix }} \mathrm{L}_{\mathrm{fix}} \mathrm{W}_{\text {fix }}$ ). The components of the total change associated with the radiative effects of (b) water vapor, (c) LW clouds, and (d) SW clouds are also shown. In each panel, the solid black line shows the simulated change in $P-E$, the blue line is the mean thermodynamic component, the solid red line is the mean dynamic component, the dashed red line is the portion of the mean dynamic component associated with changes in the divergent flow [see (3)], the cyan line is the transient eddy component, and the magenta line is the nonlinear component. The dashed black line in (a) indicates the sum of the mean thermodynamic, mean dynamic, transient eddy, and nonlinear components. The atmospheric moisture budget decomposition is defined in section $3 \mathrm{a}$.

vapor and clouds are LW absorbers with associated greenhouse effects (Fig. 6a) that tend to warm the axisymmetric monsoon core (Fig. 7a) and accelerate the circulation. The analyses in this section highlight that clouds and water vapor are key factors controlling the strong, off-equatorial, July-mean overturning circulation identified as the axisymmetric monsoon. In the next section the roles of clouds and water vapor in modulating axisymmetric monsoon onset will be examined.

\section{c. Axisymmetric monsoon onset: Role of cloud and water vapor feedbacks}

The onset of an axisymmetric monsoon is characterized by a sharp transition in near-surface zonal wind from easterly to westerly (e.g., Bordoni and Schneider 2008). Onset is rapid compared to the seasonal cycle of solar insolation that drives the monsoon (Boos and Emanuel 2009), with the rate of onset linked to a variety of factors including the wind-evaporation feedback (Boos and Emanuel 2008; Geen et al. 2019), Earth's rotation rate (Geen et al. 2019) and dynamical feedbacks between transient eddies and the upper-level monsoon circulation (Schneider and Bordoni 2008).
Here the seasonal cycle simulations (Table 1) along with the surface energy budget are used to examine the effects of clouds and water vapor on axisymmetric monsoon onset. Although a number of previous studies have investigated processes controlling onset (Schneider and Bordoni 2008; Boos and Emanuel 2008; Geen et al. 2019), here the radiative effects of clouds and water vapor on onset date will be examined in detail.

Following Bordoni and Schneider (2008), axisymmetric monsoon onset is defined as the day at which the zonal wind at $850 \mathrm{hPa}$ reverses from easterly to westerly. The goal is to develop an understanding of how feedbacks between clouds, water vapor and radiation affect the timing of monsoon onset. Specifically, the extent to which seasonally varying clouds and water vapor expedite or delay the date of monsoon onset compared to a basic state in which only insolation varies seasonally will be investigated. The focus here is on a single latitude $\left(15^{\circ} \mathrm{N}\right)$. But it should be noted that axisymmetric monsoon onset occurs on different days at different latitudes in aquaplanet simulations (e.g., Geen et al. 2019), and that the influences of cloud and water vapor feedbacks on onset are likely to vary quantitatively with latitude. 

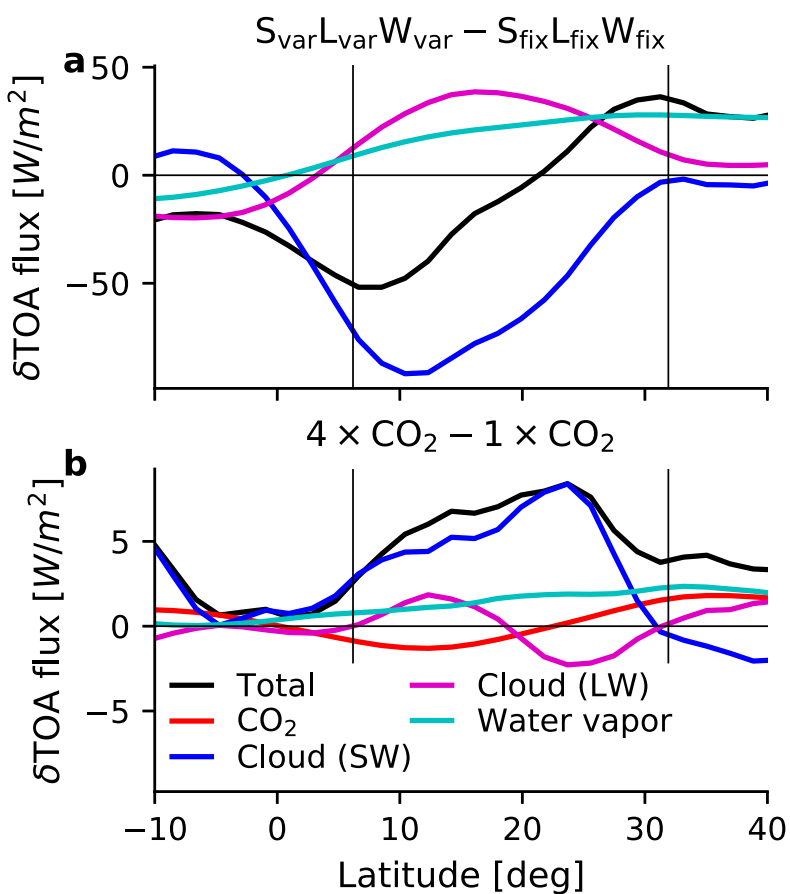

FIG. 6. Differences in top-of-atmosphere radiative fluxes (black lines) between (a) simulations with seasonally varying and annualmean cloud and water vapor profiles $\left(\mathrm{S}_{\mathrm{var}} \mathrm{L}_{\mathrm{var}} \mathrm{W}_{\mathrm{var}}\right.$ minus $\left.\mathrm{S}_{\text {fix }} \mathrm{L}_{\text {fix }} \mathrm{W}_{\text {fix }}\right)$ and (b) the perturbed and control simulations $(4 \times$ $\mathrm{CO}_{2}$ minus $1 \times \mathrm{CO}_{2}$ ). The components due to $\mathrm{CO}_{2}$ forcing (red line), SW cloud effects (blue lines), LW cloud effects (magenta lines), and water vapor (cyan lines) are also shown. Fluxes are defined as positive downward such that a positive change represents an increased energy flux into the climate system.

The simulation in which clouds and water vapor are locked to their annual-mean profiles $\left(\mathrm{S}_{\mathrm{fix}} \mathrm{L}_{\mathrm{fix}} \mathrm{W}_{\mathrm{fix}}\right)$ produces a characteristically sharp axisymmetric monsoon onset at day 176 (Fig. 8a). When seasonally varying cloud and water vapor effects are activated, the day of monsoon onset shifts (Fig. 9a): radiative effects of water vapor delay axisymmetric monsoon onset by 9 days, and the LW cloud effect delays onset by 7 days. Opposing these processes is the SW cloud effect, which expedites monsoon onset by 13 days. The radiative effects of clouds and water vapor are clearly an important influence on axisymmetric monsoon onset and in the next section a conceptual model is introduced to explain why.

\section{d. A conceptual model for monsoon onset}

To understand the physics controlling axisymmetric monsoon onset and how it is influenced by clouds and water vapor, the relationship between monsoon onset, solar insolation, and SST is considered (Fig. 8). An emerging paradigm views the monsoon as a seasonal, off-equatorial manifestation of the ITCZ (Privé and

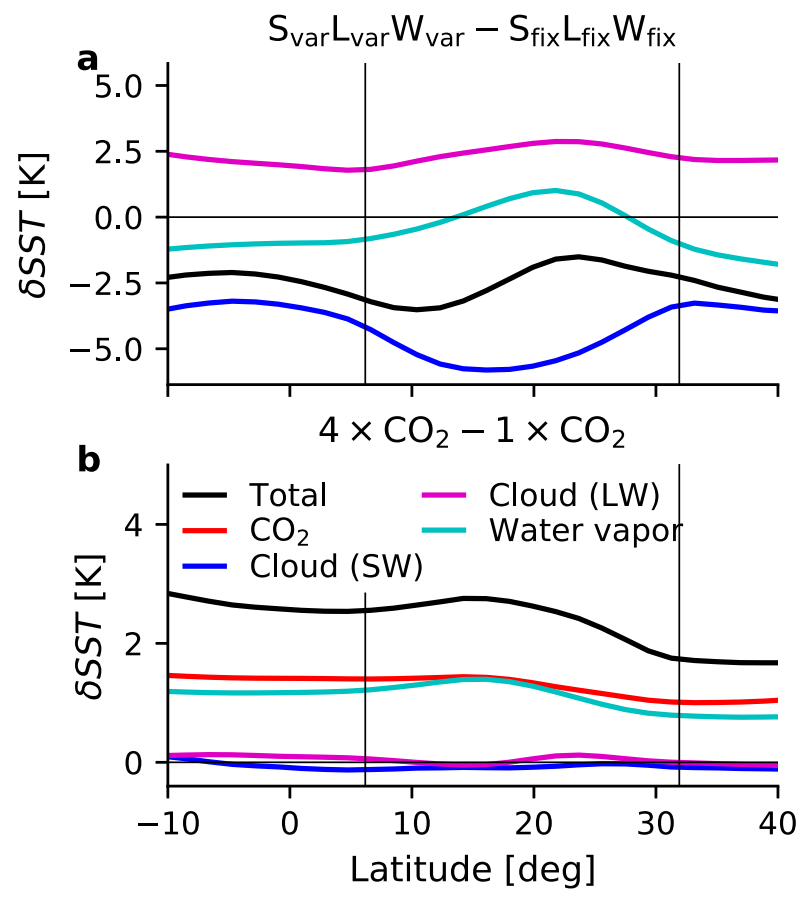

FIG. 7. Differences in sea surface temperature (black lines) between (a) simulations with seasonally varying and annual-mean cloud and water vapor profiles $\left(\mathrm{S}_{\mathrm{var}} \mathrm{L}_{\mathrm{var}} \mathrm{W}_{\mathrm{var}}\right.$ minus $\left.\mathrm{S}_{\mathrm{fix}} \mathrm{L}_{\mathrm{fix}} \mathrm{W}_{\text {fix }}\right)$ and (b) the perturbed and control simulations $\left(4 \times \mathrm{CO}_{2}\right.$ minus $1 \times$ $\mathrm{CO}_{2}$ ). The components of the total changes due to $\mathrm{CO}_{2}$ forcing (red line), SW cloud effects (blue lines), LW cloud effects (magenta lines), and water vapor (cyan lines) are also shown.

Plumb 2007; Gadgil 2018). As the latitude of maximum insolation moves off the equator (Fig. 8b), surface warming is induced (Fig. 8c), which drives a strong, cross-equatorial overturning circulation that is identified as the monsoon. The SST response lags insolation by tens of days in the axisymmetric monsoon region (Fig. 10), with the lag related to surface heat capacity (Donohoe and Battisti 2013). SST drops following axisymmetric monsoon onset (Fig. 8c), primarily due to the wind-evaporation feedback (Geen et al. 2019) and in qualitative agreement with the behavior of observed monsoons (e.g., Simpson 1921). Theory and axisymmetric models have identified a strong coupling between off-equatorial heating and the monsoon circulation (e.g., Lindzen and Hou 1988; Plumb and Hou 1992; Privé and Plumb 2007). For example, the monsoon in an axisymmetric model is found to rapidly intensify as a subtropical SST perturbation is increased beyond a critical threshold (Privé and Plumb 2007). This SST-circulation coupling suggests that the seasonal evolution of SST influences monsoon onset, transforming the problem of understanding onset into a potentially more tractable problem: What controls the seasonal cycle of subtropical SSTs? 

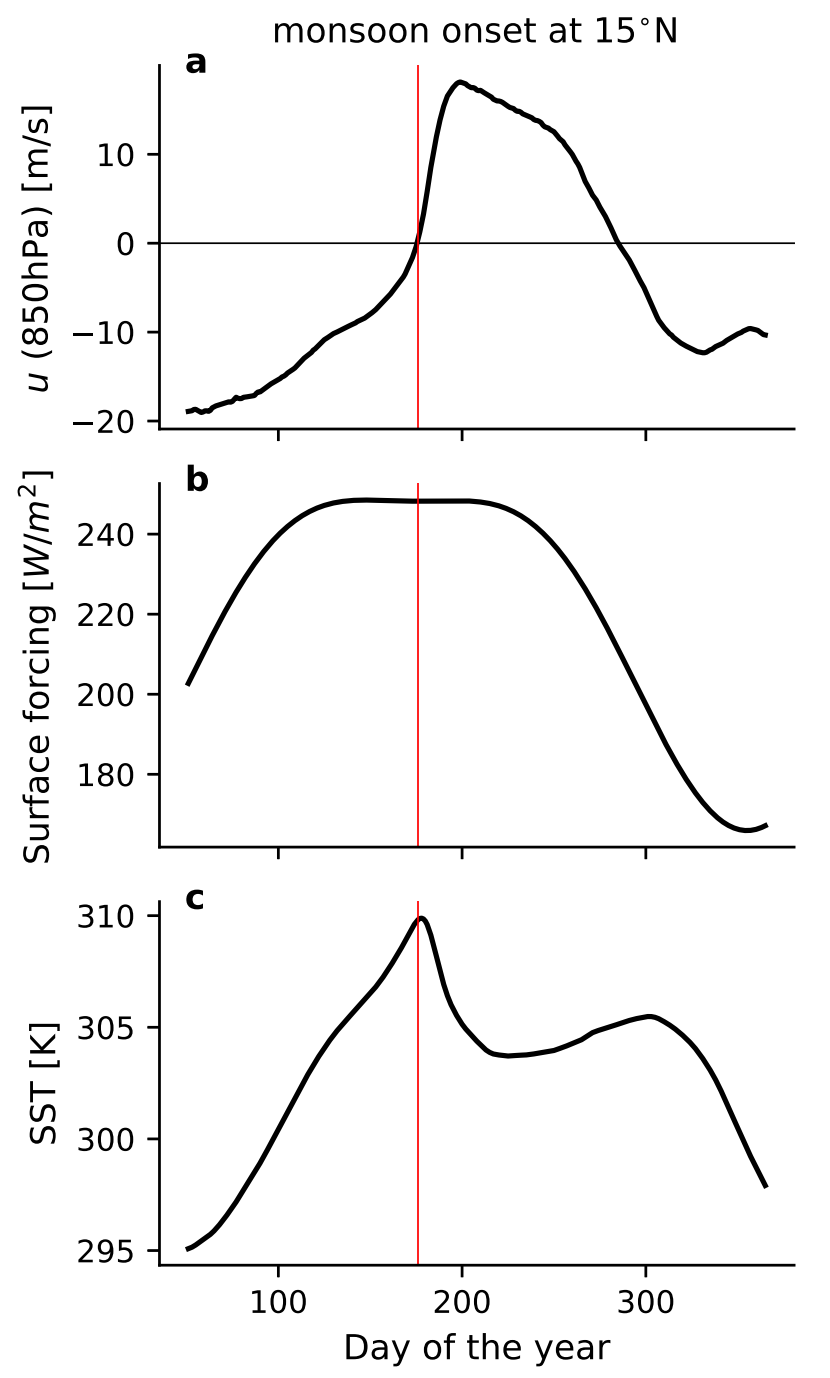

FIG. 8. Climatological daily (a) zonal wind at $850 \mathrm{hPa}$, (b) surface forcing, and (c) sea surface temperature at $15^{\circ} \mathrm{N}$ for the $\mathrm{S}_{\text {fix }} \mathrm{L}_{\text {fix }} \mathrm{W}_{\text {fix }}$ simulation. The surface forcing is defined as the net SW flux into the surface. The vertical red lines indicate the day of axisymmetric monsoon onset.

To answer this question, a simplified form of the surface energy budget with a linear feedback term is invoked:

$$
C_{s} \frac{d T_{s}}{d t}=F_{s}-\lambda T_{s}
$$

where $C_{s}$ is the surface heat capacity (equivalent, in the slab-ocean simulations, to the heat capacity of $5 \mathrm{~m}$ of liquid water), $T_{s}$ is the SST anomaly, $F_{s}$ is the surface forcing due to the seasonal cycle of insolation, and $\lambda$ is a constant surface feedback parameter. The surface forcing is defined as the net SW flux into the surface for the simulation with prescribed annual-mean cloud and water vapor profiles (i.e., $\mathrm{S}_{\mathrm{fix}} \mathrm{L}_{\mathrm{fix}} \mathrm{W}_{\mathrm{fix}}$; see Table 1);

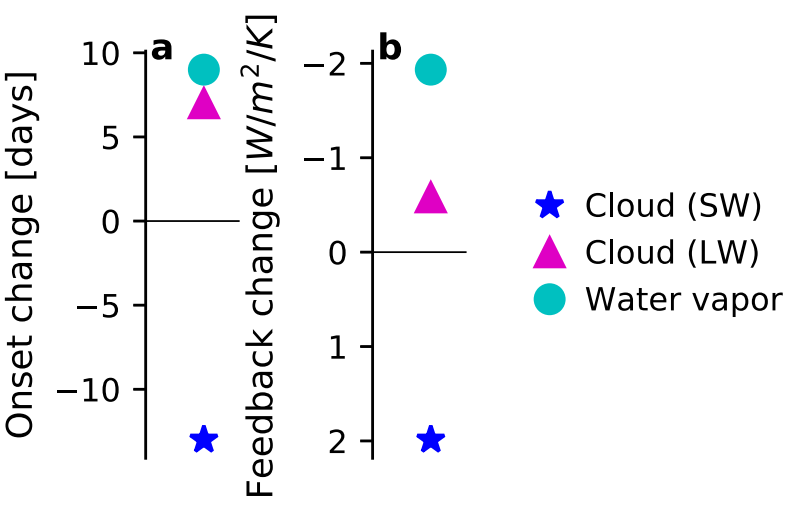

FIG. 9. Changes in (a) axisymmetric monsoon onset and (b) surface feedback parameter relative to the $\mathrm{S}_{\text {fix }} \mathrm{L}_{\text {fix }} \mathrm{W}_{\text {fix }}$ simulation. Components of the onset and feedback changes associated with seasonal SW cloud effects (blue stars), LW cloud effects (magenta triangles), and water vapor (cyan circles) are indicated. Note that the $y$ axis in (b) has been inverted.

additional surface fluxes are interpreted as temperaturedependent feedbacks driven by this forcing. The surface forcing at $15^{\circ} \mathrm{N}$ is shown in Fig. $8 \mathrm{~b}$.

Equation (4) states that the rate of change of SST at a given latitude is controlled by the seasonal cycle of insolation $F_{s}$, the heat capacity of the surface $C_{s}$, and the efficiency with which the surface dissipates heat to the overlying atmosphere (i.e., the feedback term $-\lambda T_{s}$ ). The feedback term parameterizes net surface turbulent (sensible + latent) and radiative heat fluxes as being linearly proportional to the SST anomaly. Taking the Laplace transform of (4) leads to a complex transfer function $H(f)$ that maps a periodic surface forcing at

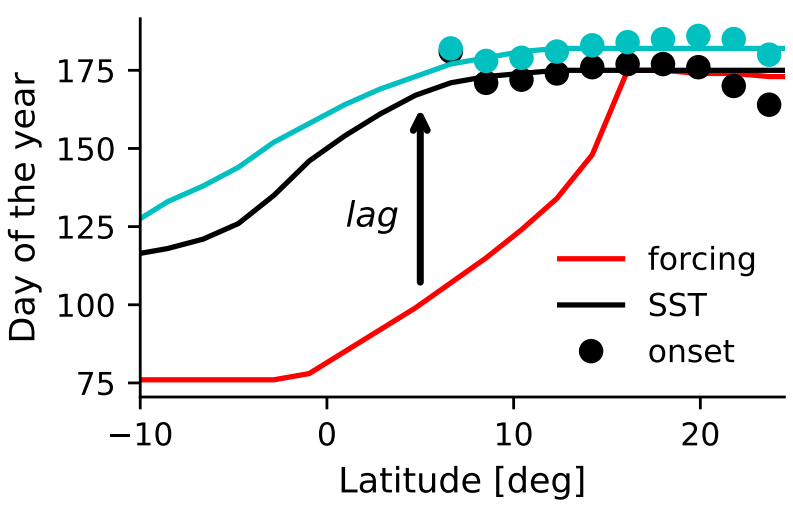

FIG. 10. Day of the year at which surface forcing (red line) and SST (black line) maximize at each latitude for the $\mathrm{S}_{\mathrm{fix}} \mathrm{L}_{\mathrm{fix}} \mathrm{W}_{\text {fix }}$ simulation. Black dots indicate the day of axisymmetric monsoon onset at each latitude, which closely track the days at which SST maximize in these simulations. The cyan line and dots show, respectively, the day when SST maximizes and monsoon onset for the $\mathrm{S}_{\text {fix }} \mathrm{L}_{\text {fix }} \mathrm{W}_{\text {fix }}$ simulation, which includes seasonally varying water vapor in the radiation code. 
frequency $f$ to the induced SST response (MacMynowski et al. 2011):

$$
H(f)=\frac{1}{2 \pi f C_{s} i+\lambda} .
$$

The magnitude of the transfer function $H(f)$ is the amplitude of the SST response to the periodic forcing. The phase

$$
\Phi=\tan ^{-1}\left(\frac{-2 \pi f C_{s}}{\lambda}\right)=\tan ^{-1}\left(-2 \pi f \tau_{s}\right)
$$

quantifies the lead or lag of the SST response relative to the forcing. In (6) a surface response time scale $\tau_{s}=C_{s} / \lambda$ has been defined. Increasing the heat capacity $C_{s}$ increases the lag between forcing and SST response by increasing the response time scale, whereas increasing the feedback parameter $\lambda$ decreases the lag. We will now use the phase of the transfer function (6) to interpret how the radiative effects of clouds and water vapor influence axisymmetric monsoon onset.

Simulations with seasonally varying water vapor show a longer lag between surface forcing and axisymmetric monsoon onset (Figs. 9a and 10). Previously identified coupling between off-equatorial SSTs and the axisymmetric monsoon (e.g., Lindzen and Hou 1988; Plumb and Hou 1992; Privé and Plumb 2007) suggests that this shift in the timing of monsoon onset is related to the lag between surface forcing and SST response, quantified by (6). The heat capacity $C_{s}$ and forcing frequency $f$ are fixed across all simulations, so according to (6) the longer lag is due to a decrease in the surface feedback parameter $\lambda$. The feedback parameter for each simulation in Table 1 is estimated by analyzing SSTs and surface heat fluxes (with the surface forcing removed) in the lead up to axisymmetric monsoon onset. In particular, $\lambda$ is computed for each simulation by integrating (4) from 50 days prior to onset up to the day of monsoon onset. The feedback parameter is interpreted physically as the efficiency with which the surface cools via radiative and turbulent fluxes.

The delayed axisymmetric monsoon onset in simulations with seasonally varying water vapor (Fig. 10) is qualitatively consistent with a reduction in the feedback parameter relative to simulations with a fixed annualmean water vapor profile (Fig. 9b). The magnitude of the water vapor feedback (approximately $2 \mathrm{~W} \mathrm{~m}^{-2} \mathrm{~K}^{-1}$ ) at the surface is similar to TOA estimates (Dessler et al. 2008). The delayed monsoon onset is physically intuitive: When the water vapor feedback is active, the associated greenhouse effect increases the net downwelling LW flux into the surface, inhibits surface cooling, reduces the feedback parameter and lengthens the surface response time scale (6). Similar arguments can be made for the effects of clouds on axisymmetric monsoon onset. The seasonal LW cloud feedback acts in a similar way to the water vapor feedback (Fig. 9). The warming LW greenhouse effect of clouds restricts surface cooling, decreases the feedback parameter (Fig. 9b) and delays onset (Fig. 9a). The SW cloud feedback, on the other hand, enhances the cooling ability of the surface by reflecting incoming SW radiation back to space. By making it easier for the surface to cool, the SW effect of clouds increases the feedback parameter (Fig. 9b) and expedites axisymmetric monsoon onset by approximately two weeks (Fig. 9a). Across all seasonal simulations (Table 1) there is an anticorrelation between the day of axisymmetric monsoon onset and the feedback parameter $(r=-0.74)$, suggesting a mechanistic link between axisymmetric monsoon onset and the efficiency of surface cooling.

The lag between forcing and SST response, and the timing of monsoon onset, depend on surface heat capacity and mixed-layer depth (6). The influences of water vapor and cloud feedbacks on monsoon onset will therefore be modified quantitatively in simulations with different mixed-layer depths. For example, a given water vapor feedback will have a weaker effect on the timing of monsoon onset in a simulation with a deeper mixed layer. However, the qualitative impacts of water vapor and clouds on monsoon onset, and the conceptual framework described above, are expected to be applicable-following further development-to monsoons in full-complexity models and in the real Earth system. For example, the conceptual model could be extended to understand the effects of clouds and water vapor on the seasonal evolution of SST gradients, which are known to shape tropical circulations (Lindzen and Nigam 1987; Plumb and Hou 1992; Emanuel 1995) and have been put forward as a key influence on monsoon onset (Schneider and Bordoni 2008; Geen et al. 2019).

\section{Radiative effects on an axisymmetric monsoon: Climate change}

The radiation-locking simulations listed in Table 2 and described in section $2 \mathrm{~d}$ are now used to investigate how cloud and water vapor feedbacks-in addition to $\mathrm{CO}_{2}$ forcing-influence the axisymmetric monsoon response to climate change. See the appendix for a detailed description of how the $\mathrm{CO}_{2}$, water vapor, and cloud contributions to the climate change response are calculated.

\section{a. Influence of $\mathrm{CO}_{2}$ forcing versus cloud and water vapor feedbacks}

The axisymmetric monsoon response to an abrupt quadrupling of $\mathrm{CO}_{2}$ is decomposed into contributions 


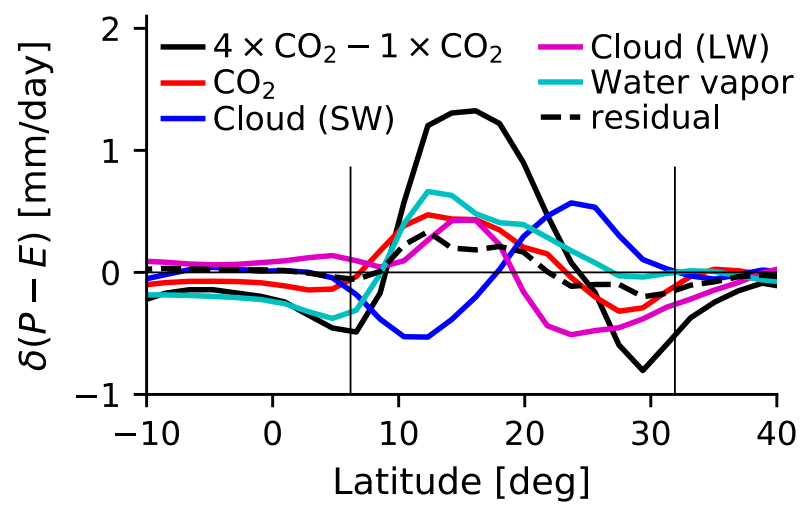

FIG. 11. Differences in precipitation minus evaporation (solid black line) between the perturbed and control simulations $(4 \times$ $\mathrm{CO}_{2}$ minus $1 \times \mathrm{CO}_{2}$ ). The components of the total change are also shown: $\mathrm{CO}_{2}$ forcing (red line), SW cloud feedback (blue line), LW cloud feedback (magenta line), and the water vapor feedback (cyan line). The dashed black line is the residual term showing the effect of nonlinear interactions between $\mathrm{CO}_{2}$, clouds, and water vapor on the monsoon response (see appendix).

from $\mathrm{CO}_{2}$ forcing, the water vapor feedback, and cloud feedbacks (SW and LW); each contribution substantially influences the total axisymmetric monsoon response to climate change (Fig. 11). The $\mathrm{CO}_{2}$ and water vapor components have similar magnitudes and meridional structures: both strengthen and moisten the core of the axisymmetric monsoon (increase $P-E$ ) and tend to weaken and dry the axisymmetric monsoon near its boundaries. Water vapor and $\mathrm{CO}_{2}$ are both greenhouse gases, so it is not surprising that their effects on the axisymmetric monsoon are similar. The cloud components have comparable magnitudes to the $\mathrm{CO}_{2}$ and water vapor terms but distinctive dipole-like spatial structures (Fig. 11). The SW cloud feedback strengthens (moistens) the poleward side of the axisymmetric monsoon and weakens (dries) the equatorward side. The LW cloud component is almost the mirror image of the SW component, drying the poleward side and moistening the equatorward side of the axisymmetric monsoon. The residual term is smaller than each of the other components though contributes to moistening of the monsoon region (Fig. 11); the residual would be zero if the radiative effects of $\mathrm{CO}_{2}$, clouds, and water vapor were fully independent (see the appendix).

The axisymmetric monsoon location migrates equatorward in response to $\mathrm{CO}_{2}$ quadrupling (Fig. 4a). This equatorward shift is driven partly by $\mathrm{CO}_{2}$ forcing and partly by the water vapor and LW cloud feedbacks. Acting by itself, the LW cloud feedback would shift the axisymmetric monsoon equatorward by approximately $1^{\circ}$, but this shift is more than cancelled out by the SW cloud feedback which acts to shift the axisymmetric monsoon poleward. The components of the change in axisymmetric monsoon location are consistent with the patterns of changes in $P-E: \mathrm{CO}_{2}$, water vapor, and the LW cloud feedback predominantly moisten the equatorward side of the axisymmetric monsoon (Fig. 11), which shifts the $P-E$ maximum toward the equator. In contrast, the SW cloud feedback opposes the equatorward shift by moistening the axisymmetric monsoon on its poleward side and drying on its equatorward side.

The axisymmetric monsoon narrows by approximately $1^{\circ}$ in response to $\mathrm{CO}_{2}$ quadrupling (Fig. 4b). All radiative effects contribute to this narrowing, with the LW cloud feedback exerting the strongest influence. Again, axisymmetric monsoon narrowing is consistent with patterns of $P-E$ changes driven by the various radiative effects, with most terms tending to drive drying at the edges of the axisymmetric monsoon hence narrowing it (Fig. 11). The axisymmetric monsoon strengthens by almost $20 \%$ when $\mathrm{CO}_{2}$ is quadrupled (Fig. $4 \mathrm{c}$ ), and this strengthening is driven roughly equally by $\mathrm{CO}_{2}$ forcing, water vapor, and cloud feedbacks.

\section{b. Dynamic versus thermodynamic effects on the axisymmetric monsoon response to climate change}

As for the climatological monsoon, the atmospheric moisture budget is analyzed to understand the respective roles of changes in specific humidity versus changes in circulation for controlling the axisymmetric monsoon response to climate change.

\section{1) TOTAL MONSOON RESPONSE}

The total $P-E$ response between the control simulation $\left(1 \times \mathrm{CO}_{2}\right)$ and the perturbed simulation $(4 \times$ $\mathrm{CO}_{2}$ ) -with strong moistening in the axisymmetric monsoon core and drying on the flanks (Fig. 11) - is dominated by the mean thermodynamic term (2), which moistens the axisymmetric monsoon region and dries the latitudes immediately south of it (Fig. 12a). This is the simple "wet-get-wetter, dry-get-drier" scaling in action: In a warming climate, relative humidity remains approximately constant (e.g., Held and Soden 2000), implying increases in specific humidity and an amplification of the climatological $P-E$ pattern at the ClausiusClapeyron rate of approximately $7 \% \mathrm{~K}^{-1}$ (Mitchell et al. 1987; Chou and Neelin 2004; Held and Soden 2006; Chou et al. 2009). The mean thermodynamic component defined by (2) includes changes in relative humidity and horizontal temperature gradients, additional effects that are neglected in the "wet-get-wetter, dry-get-drier" scaling. Although these effects are important over land (Byrne and O'Gorman 2015) and for $P-E$ changes between the present day and the Last Glacial Maximum (Boos 2012), they are found to be negligible in the aquaplanet simulations presented here (not shown). 


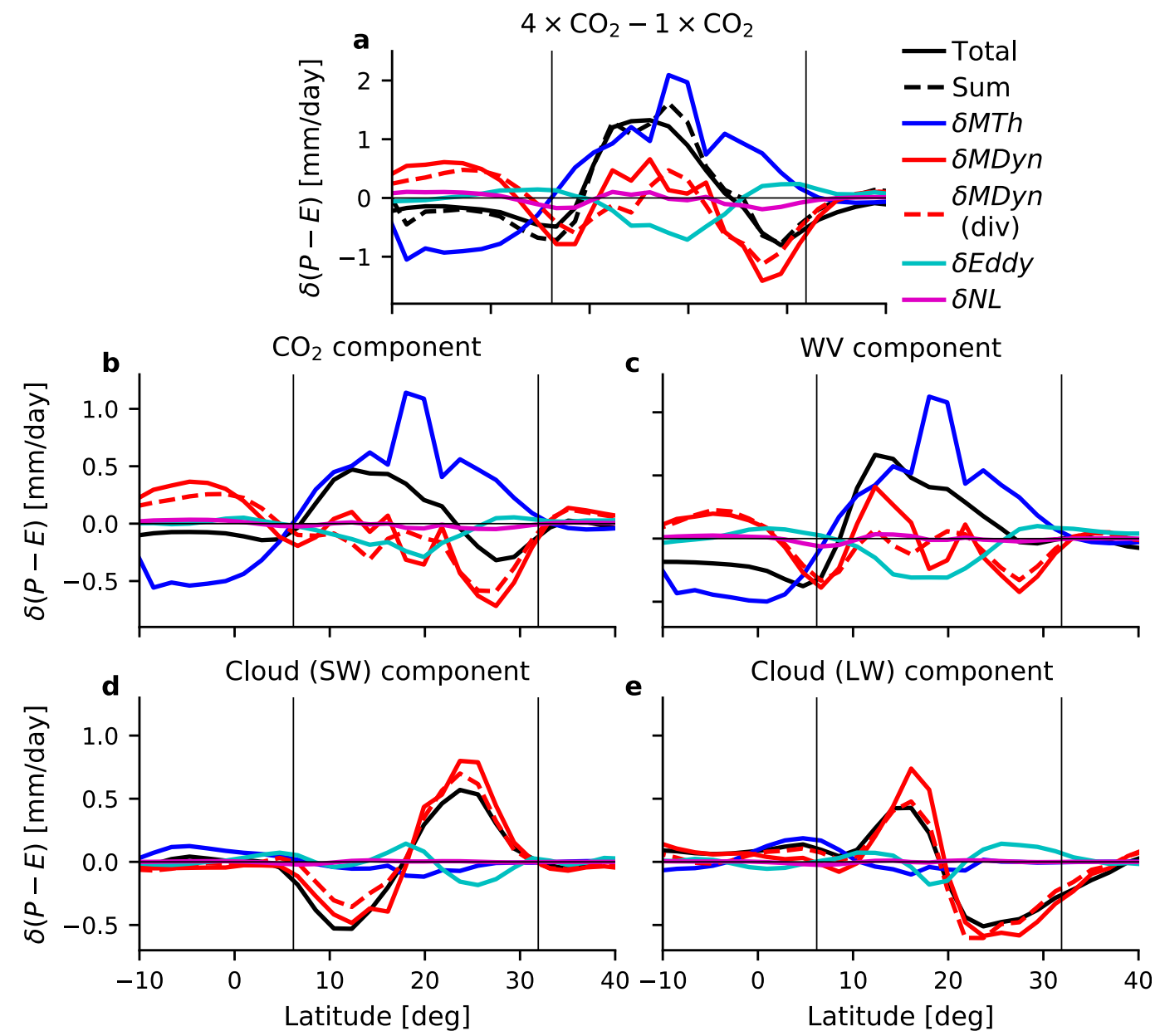

FIG. 12. Difference in precipitation minus evaporation (a) between the perturbed and control simulations $(4 \times$ $\mathrm{CO}_{2}$ minus $1 \times \mathrm{CO}_{2}$ ) and the components associated with (b) $\mathrm{CO}_{2}$ forcing, (c) water vapor feedback, (d) SW cloud feedback, and (e) LW cloud feedback. The contributions to the $P-E$ changes from thermodynamic, dynamic, transient eddy, and nonlinear processes are shown in each panel, and the dashed black line in (a) indicates the sum of these contributions. The dashed red lines show the contributions of changes in the divergent flow to the mean dynamic components.

The mean thermodynamic term is the largest contribution to the total axisymmetric monsoon response. But the influence of changes in mean circulation is substantial, particularly on the flanks of the monsoon (Fig. 12a). In these regions the circulation weakens, tending to dry the axisymmetric monsoon $[\delta(P-E)<0]$ and oppose thermodynamically driven increases in $P-E$. This weakening of the axisymmetric monsoon circulation is consistent with the results of Shaw and Voigt (2015), who found that the "indirect effect" of SST warming reduces the strength of the Asian monsoon cyclone. As for the climatological monsoon the mean dynamic term is dominated by its divergent component (3), highlighting that changes in vertical velocity and the overturning circulation are important for responses on both the equatorward and poleward sides of the axisymmetric monsoon region (Fig. 12a). Transient eddies exert a weaker influence on the axisymmetric monsoon relative to the mean thermodynamic and dynamic terms, drying the core of the axisymmetric monsoon and moistening the flanks modestly (Fig. 12a). The nonlinear term is negligible and is not discussed further.

\section{2) $\mathrm{CO}_{2}$ AND WATER VAPOR COMPONENTS}

The processes controlling how $\mathrm{CO}_{2}$ forcing (Fig. 12b) and the water vapor feedback (Fig. 12c) impact the axisymmetric monsoon are similar to one another and to the total $P-E$ response (cf. Fig. 12a). The mean thermodynamic term is the dominant influence, with changes in the mean divergent circulation and in transient eddies tempering the thermodynamically induced monsoon moistening (Figs. 12b,c). Interestingly, $\mathrm{CO}_{2}$ 
forcing and the water vapor feedback affect the magnitude and spatial pattern of axisymmetric monsoon $P-E$ in very similar ways, which is consistent with $\mathrm{CO}_{2}$ and water vapor driving large SST changes with approximately equal magnitudes and similar meridional structures (Fig. 7b).

\section{3) Cloud COMPONENTS}

Clouds affect the axisymmetric monsoon response to climate change in an entirely different way to $\mathrm{CO}_{2}$ and water vapor (Figs. 12d,e). The magnitudes of the changes in $P-E$ induced by cloud feedbacks are comparable to the $\mathrm{CO}_{2}$ and water vapor changes, but the patterns are wholly different. Strikingly, both the SW and LW cloud components of the $P-E$ response are driven almost completely by mean circulation changes (Figs. 12d,e), in contrast to the $\mathrm{CO}_{2}$ and water vapor components, which are mostly associated with thermodynamic changes (cf. Figs. 12b,c). Clouds have a negligible influence on SST in the axisymmetric monsoon region (Fig. 7b), yet perturb TOA fluxes substantially (Fig. 6b). That clouds strongly control the axisymmetric monsoon yet have a negligible influence on SST suggests that established theories for the tropical circulation based on SST patterns (e.g., Lindzen and Nigam 1987; Sobel 2007; Back and Bretherton 2009; Duffy et al. 2020) are unlikely to explain how cloud feedbacks impact monsoons in a changing climate.

Clouds are an essential process shaping the axisymmetric monsoon, but the pathway by which clouds exert this influence is dynamic rather than thermodynamic. Dynamic (or circulation) responses to climate change are generally less certain than thermodynamic responses (Shepherd 2014), although they are important to understand if projections of monsoons in future climates are to be better constrained. In the next section the strong coupling between clouds and circulation will be used to further investigate the key influence of clouds on the axisymmetric monsoon circulation in a changing climate.

\section{c. Toward understanding how cloud feedbacks impact the axisymmetric monsoon circulation}

The axisymmetric monsoon responses to $\mathrm{CO}_{2}$ forcing and the water vapor feedback are determined primarily by thermodynamic processes associated with warming SSTs in the monsoon region. Dynamic changes in the axisymmetric monsoon associated with $\mathrm{CO}_{2}$ and water vapor affect the meridional pattern of the $P-E$ response and tend to narrow the monsoon in a warming climate, but are small relative to the thermodynamic changes (Figs. 12b,c). In contrast, circulation changes dominate the response of the axisymmetric monsoon to cloud feedbacks (Figs. 12d,e) and strongly influence the location, width, and strength of the axisymmetric monsoon in a changing climate. In this section the changes in axisymmetric monsoon circulation in response to the cloud feedbacks imposed in the radiation-locking simulations are analyzed in further detail.

Clouds induce only subtle changes in SST within the axisymmetric monsoon region in response to $\mathrm{CO}_{2}$ forcing (Fig. 7b), suggesting that the class of theories linking tropical circulations to the SST distribution [for a review see Sobel (2007)] are unlikely to explain the large changes in circulation induced by clouds. An alternative approach would be to use the atmospheric moist static energy budget to understand how the axisymmetric monsoon circulation responds to surface or TOA energy perturbations (e.g., Neelin and Held 1987; Kang et al. 2008; Bischoff and Schneider 2014; Hill 2019). Such an approach would rely on an energy perturbation at the boundary being balanced primarily by changes in the mean divergent axisymmetric monsoon circulation, rather than by changes in energy stratification or transient eddy transport. However, in the simulations presented here, the energy perturbations driven by clouds are primarily balanced by transient eddies rather than by changes in the mean circulation (not shown). Consequently, the atmospheric energy budget is not particularly useful for constructing arguments for how clouds influence the axisymmetric monsoon.

Here the strong coupling between clouds and circulation is invoked to partially explain how cloud feedbacks influence the axisymmetric monsoon circulation. In the tropics, the SW and LW cloud radiative effects are tightly coupled to midtropospheric vertical velocity (e.g., Bony et al. 2004). There is a straightforward explanation for this: Clouds are thicker, deeper, and more prevalent in regions of strongly ascending air (e.g., monsoons), so their radiative effects are stronger. Moving toward regions of weakly ascending and subsiding air, clouds tend to be thinner, lower in the atmosphere, and less prevalent and therefore have weaker radiative effects. Typically, the robust relationship between cloud radiative effect and vertical velocity has been used to understand cloud feedbacks in response to increasing SSTs (Bony et al. 2004; Wyant et al. 2006; Byrne and Schneider 2018). Here, in contrast, the cloud-circulation relationship will be used to understand the axisymmetric monsoon response to cloud feedbacks imposed using the radiation-locking technique.

The control simulation shows strong coupling between midtropospheric vertical velocity and the SW and LW cloud radiative effects in the axisymmetric monsoon region (Fig. 13). Cloud radiative effects are defined in the conventional way as differences between all-sky and 

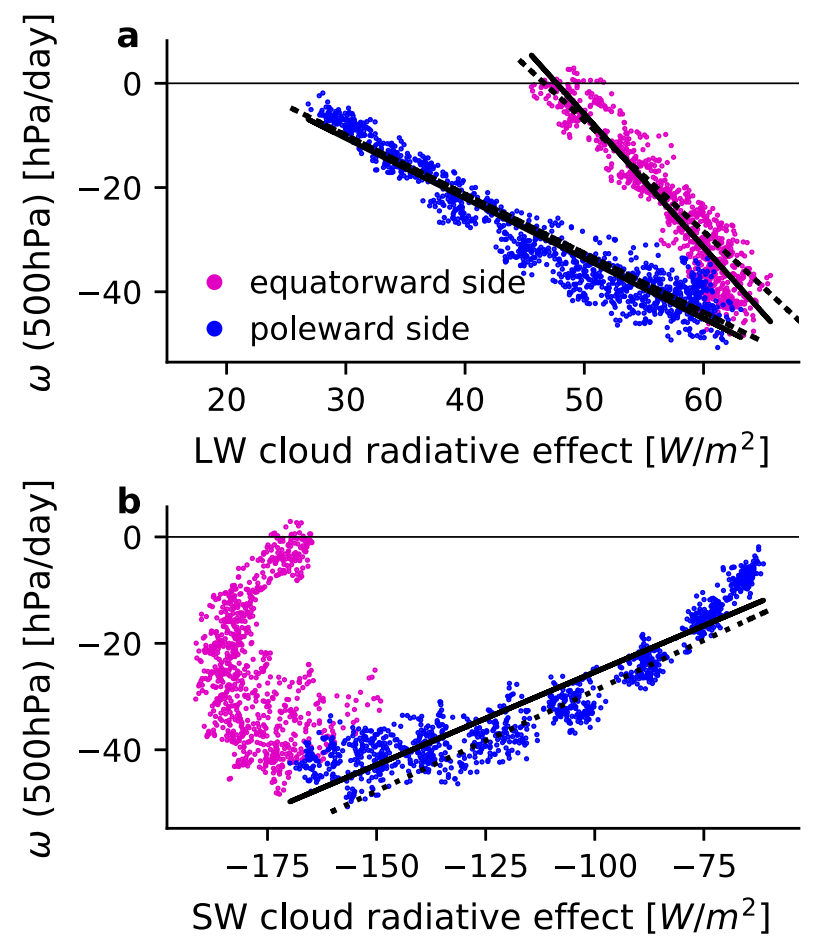

FIG. 13. Vertical velocity at $500 \mathrm{hPa}$ as a function of (a) LW and (b) SW cloud radiative effect for the control $\left(1 \times \mathrm{CO}_{2}\right)$ simulation. Blue dots show July data from grid points on the poleward side of the axisymmetric monsoon (from $18^{\circ}$ to $32^{\circ} \mathrm{N}$ ) and magenta dots show July data from the equatorward side (from $6^{\circ}$ to $18^{\circ} \mathrm{N}$ ). The thick solid black lines are linear least squares fits to the data from the control simulation (the poleward and equatorward sides are fitted separately). The dotted black lines are linear fits between vertical velocity and the cloud radiative effects in the perturbed simulations where in (a) only the LW cloud feedback is applied and in (b) only the SW cloud feedback is applied.

clear-sky radiative fluxes at the TOA (Allan 2011), with positive values indicating that clouds are adding energy to the climate system. For the LW cloud radiative effect, the larger the ascent rate in the midtroposphere the stronger the cloud heating of the axisymmetric monsoon region (Fig. 13a). There are two regimes of behavior, with a stronger dependence of LW cloud radiative effect on vertical velocity on the equatorward side of the axisymmetric monsoon versus on the poleward side. The differing sensitivities of LW cloud radiative effect to vertical velocity in each sector possibly reflect latitudinal variations in temperature and specific humidity. For the SW cloud radiative effect (Fig. 13b), on the poleward side of the axisymmetric monsoon there is a clear dependence on vertical velocity, with SW cloud cooling becoming stronger as ascent strengthens. On the equatorward side, however, the relationship between SW cloud radiative effect and vertical velocity breaks down; in this region additional factors including inversion strength (Wood and Bretherton 2006) and lower tropospheric convective mixing (Sherwood et al. 2014) are likely to affect the SW cloud radiative effect.

The climatological cloud-circulation relationships in Fig. 13 will now be leveraged to make quantitative estimates of the changes in axisymmetric monsoon circulation (specifically vertical velocity at $500 \mathrm{hPa}$ ) in response to imposed SW and LW cloud feedbacks. First, linear fits of vertical velocity $\omega$ to cloud radiative effect $R$ for the SW and LW fluxes individually, and for the equatorward and poleward sides of the axisymmetric monsoon individually, are computed:

$$
\omega(R)=a+b R,
$$

where $a$ and $b$ are fitting coefficients. In general, estimating a change in vertical velocity $\delta \omega$ in response to an imposed change in cloud radiative effect $\delta R$ requires knowledge not only of $\delta R$ but also of how the linear relationship between vertical velocity and cloud radiative effect changes with climate state. Changes in the linear relationship $\omega(R)$ are often considered to be a thermodynamic, or temperature-driven, response of the cloud radiative effect to a change in climate (Bony et al. 2004; Byrne and Schneider 2018). However, cloud feedbacks in response to $\mathrm{CO}_{2}$ quadrupling have only a limited influence on SSTs in the axisymmetric monsoon region (Fig. 7b), suggesting that the relationship between cloud radiative effect and circulation (7) may be relatively constant under an imposed cloud feedback. Comparing the linear fits of vertical velocity to LW cloud radiative effect in the control simulation $(1 \times$ $\mathrm{CO}_{2}$ ) and in a perturbed case in which only the LW cloud feedback is applied, the relationships are found to be similar (Fig. 13a). For the SW cloud radiative effect, the fit on the poleward side of the axisymmetric monsoon has a similar slope in the control simulation and for the perturbed case in which the SW cloud feedback is applied, although it is shifted downward (Fig. 13b). However, on the equatorward side of the axisymmetric monsoon there is little evidence of a linear relationship between cloud radiative effect and circulation in the control simulation (Fig. 13b), so changes in a linear relationship in response to an imposed SW cloud feedback would have little physical meaning.

Assuming the linear relationships between vertical velocity and cloud radiative effect remain roughly constant under an imposed cloud feedback, this opens up the possibility of predicting cloud-driven changes in the axisymmetric monsoon circulation as a function of changes in cloud radiative effect and the climatological relationship between clouds and circulation: 

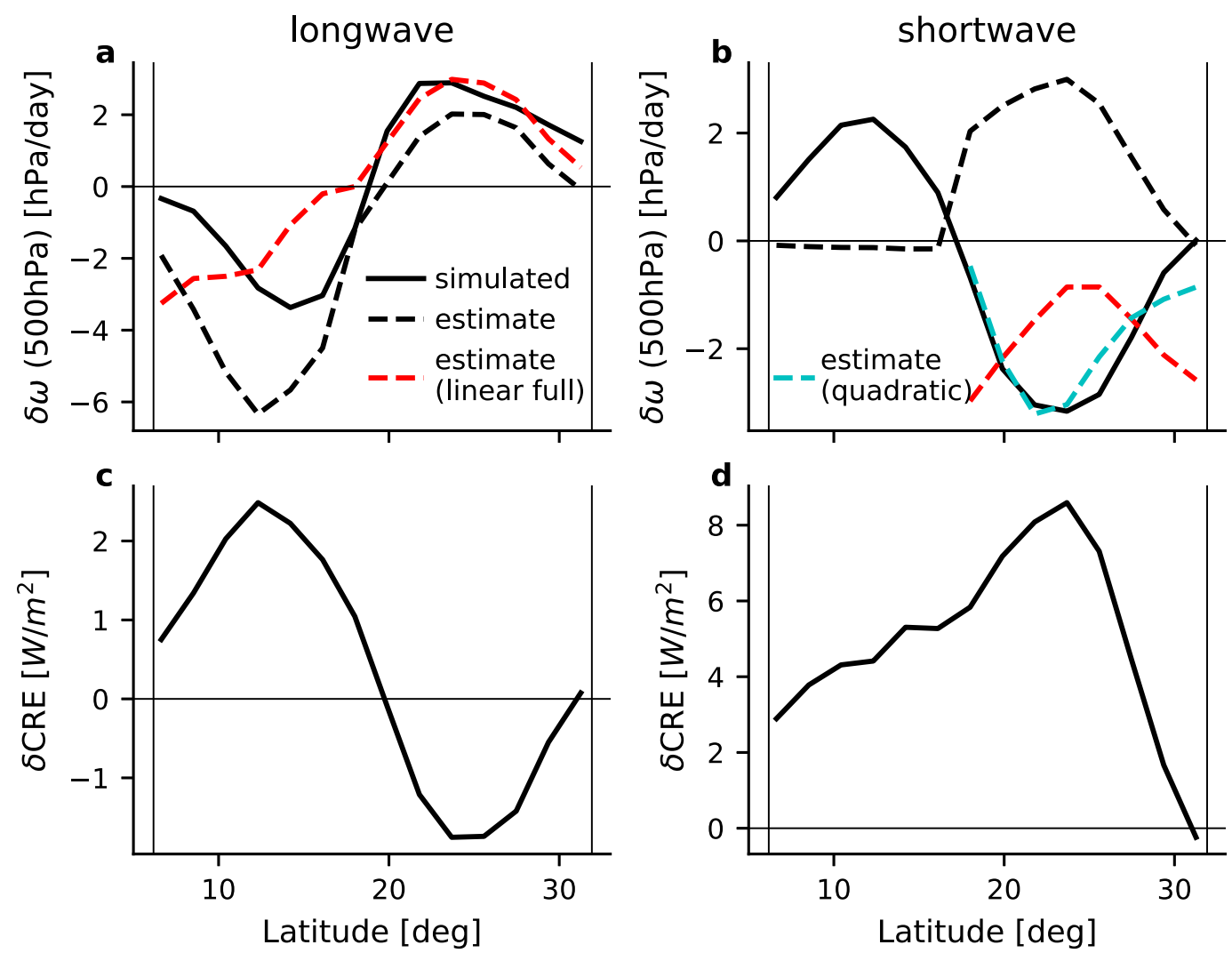

FIG. 14. Simulated (solid black lines) and estimated (dashed lines) (a) LW and (b) SW cloud components of the change in vertical velocity at $500 \mathrm{hPa}$ between the perturbed $\left(4 \times \mathrm{CO}_{2}\right)$ and control $\left(1 \times \mathrm{CO}_{2}\right)$ simulations. Several estimates are shown: 1) The dashed black lines represent estimates that are computed as a function of changes in (c) LW or (d) SW cloud radiative effect, with the assumption that the climatological relationships between vertical velocity and cloud radiative effect are constant under climate change [i.e. the coefficients $a$ and $b$ in the linear fits [(7)] stay constant as climate changes]. 2) Dashed red lines in (a) and (b) are estimates using the linear fits between vertical velocity and cloud radiative effect, but including simulated changes in the coefficients $a$ and $b$. 3) The dashed cyan line in (b) shows the estimate assuming a quadratic relationship between vertical velocity and cloud radiative effect, i.e., $\omega(R)=a+b R+c R^{2}$.

$$
\delta \omega \approx b \delta R .
$$

\section{1) RESPONSE TO LONGWAVE CLOUd FEEDBACKS}

Equation (8) is first applied to estimate the response of axisymmetric monsoon vertical velocity to changes in LW cloud radiative effect (Fig. 14a). The LW cloud feedback strengthens ascent on the equatorward side of the axisymmetric monsoon and weakens ascent on the poleward side. This dipole-like circulation response reflects changes in LW cloud radiative effect under $\mathrm{CO}_{2}$ quadrupling (Fig. 14c): A strengthening cloud radiative effect (heating) on the equatorward side of the axisymmetric monsoon is consistent with strengthening ascent, and a weakening cloud radiative effect (cooling) on the poleward side suggests weakening ascent. Increases in LW cloud radiative effect in a warming climate are generally due to rising free-tropospheric cloud tops, which represent a positive climate feedback (e.g., Ceppi et al. 2017). The decrease in LW cloud radiative effect on the poleward side of the axisymmetric monsoon (Fig. 14c) is likely associated with decreases in high-cloud amount in that region (not shown). The purpose here is to investigate how cloud feedbacks affect the axisymmetric monsoon; for detailed discussions of the feedback mechanisms themselves, see reviews by Stephens (2005), Ceppi et al. (2017), and Klein et al. (2017).

An estimate of the change in vertical velocity driven by the LW cloud feedback assuming a fixed relationship between LW cloud radiative effect and circulation [see (8)] broadly captures the pattern of simulated changes (Fig. 14a). This is an interesting result highlighting that the LW cloud feedback, imposed in the radiationlocking simulations as a forcing, drives a change in axisymmetric monsoon circulation that depends only on the radiative feedback itself and the climatological 
relationship between clouds, radiation, and vertical velocity. Clouds, primarily via their impact on circulation, are a dominant influence on the axisymmetric monsoon response to climate change (Figs. 12d,e) and so linking this response to a climatological relationship in climate models opens the possibility of developing a new "emergent constraint" for monsoons [see Klein and Hall (2015) for an elegant discussion of the concept of emergent constraints]. By allowing the coefficients $a$ and $b$ in (7) to change with climate, estimates of the change in vertical velocity are somewhat improved (this is termed the "linear full" estimate; see the red dashed line in Fig. 14a), although the estimate is qualitatively similar to assuming a constant linear relationship [(8)].

\section{2) RESPONSE TO SHORTWAVE CLOUD FEEDBACKS}

Although changes in axisymmetric monsoon circulation driven by LW cloud feedbacks can be predicted at least to zeroth order by assuming a constant linear relationship between vertical velocity and cloud radiative effect (Fig. 14a), this is not the case for circulation changes associated with SW cloud feedbacks (Fig. 14b). On the poleward side of the axisymmetric monsoon, ascent strengthens in response to a weakening of the negative SW cloud radiative effect (Fig. 14d) whereas on the equatorward side the ascent weakens. These changes are not captured by assuming a constant linear relationship between circulation and cloud radiative effect [(8)], which instead predicts an opposite-signed response of vertical velocity (weakening ascent) on the poleward side of the axisymmetric monsoon and little change on the equatorward side (Fig. 14b). On the equatorward side, as discussed, there is no clear linear relationship between vertical velocity and SW cloud radiative effect (Fig. 13b) and it is not surprising that predictions of circulation changes in that region using a linear model are not accurate. On the poleward side, there are positive changes in SW cloud radiative effect under $\mathrm{CO}_{2}$ quadrupling (Fig. 14d), implying a weakening of ascent in that region for a fixed climatological relationship between circulation and cloud radiative effect. However, this is not what the simulations show; instead the ascent increases in magnitude in response to changes in SW cloud radiative effect (Fig. 14b). Accounting for changes in the coefficients $a$ and $b$ in the linear model [(7)] improves the estimates of the changes in vertical velocity substantially (cf. the black and red dashed lines in Fig. 14b). This implies that changes in axisymmetric monsoon circulation driven by the SW cloud feedback are unlikely to be constrained or predicted as a function of the climatological cloud-circulation relationship; one would also need a theory for how that relationship evolves with climate change. A quadratic fit of the relationship between circulation and SW cloud radiative effect $\left[\omega(R)=a+b R+c R^{2}\right]$ is required to accurately estimate changes in circulation on the poleward side of the axisymmetric monsoon (see the cyan dashed line in Fig. 14b), suggesting that nonlinear interactions between SW cloud radiative effect and circulation are central to understanding how clouds affect monsoons in a changing climate.

\section{Sensitivities to water vapor and clouds: Seasonal cycle versus climate change}

By modifying energy input to the atmosphere, clouds and water vapor exert strong influences on the axisymmetric monsoon over the seasonal cycle (Fig. 3) and under climate change (Fig. 11). Temperature-driven cloud and water vapor feedbacks in response to forcings from $\mathrm{CO}_{2}$ and the seasonal cycle of insolation are different in their magnitudes and structures (Fig. 15), yet there are similarities: The water vapor and LW cloud feedbacks are positive in the axisymmetric monsoon region over the seasonal cycle and under climate change, and the SW cloud feedback is strongly negative in both cases. In simple physical terms, water vapor and LW cloud feedbacks act to further energize the axisymmetric monsoon region in a warming climate, whereas the SW cloud feedback reduces energy input. The water vapor and cloud feedbacks in response to $\mathrm{CO}_{2}$ quadrupling in the axisymmetric monsoon region (Fig. 15b) are within the ranges of comprehensive models, which show considerable intermodel spread particularly for cloud feedbacks (not shown).

The resemblance of seasonal and climate change feedbacks in the axisymmetric monsoon region motivates an additional question: Are sensitivities of the axisymmetric monsoon to changes in clouds and water vapor similar over the seasonal cycle and under climate change? Monsoon sensitivity in this context is defined to be the change in $P-E$ averaged over the axisymmetric monsoon region divided by the energy input change at TOA (which is also averaged over the monsoon region). Comparing the seasonal and climate change sensitivities (Table 3), both are positive for water vapor yet there is almost a factor of 3 difference between the magnitudes of the sensitivities. For the SW effect of clouds, the axisymmetric monsoon is much more sensitive over the seasonal cycle than under climate change. However, the LW cloud sensitivities of the axisymmetric monsoon are equal for the seasonal cycle and under climate change $\left(-0.017 \mathrm{~mm} \mathrm{day}^{-1}\right)$. This is a potentially important result in the context of future monsoons, as it suggests that the substantial influence of the LW cloud effect on the monsoon response to $\mathrm{CO}_{2}$ forcing (Fig. 11) could be constrained by observing the LW cloud feedback in monsoon regions over the seasonal cycle. This is an 

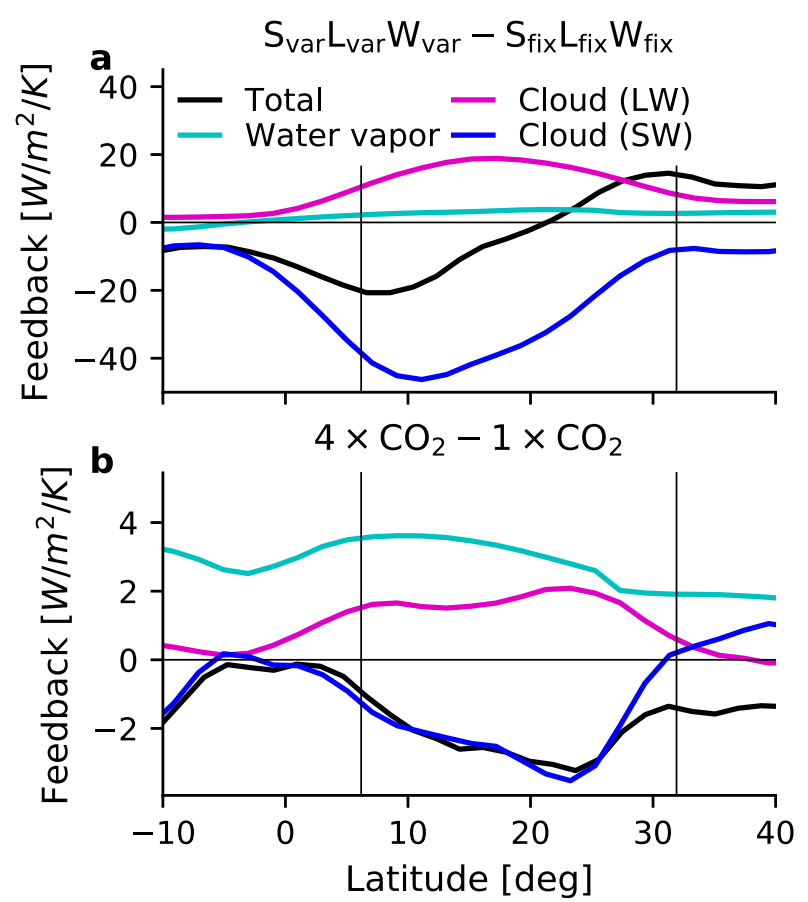

FIG. 15. Temperature-driven feedbacks between (a) simulations with seasonally varying vs annual-mean cloud and water vapor profiles $\left(\mathrm{S}_{\mathrm{var}} \mathrm{L}_{\mathrm{war}} \mathrm{W}_{\text {var }}\right.$ minus $\left.\mathrm{S}_{\text {fix }} \mathrm{L}_{\text {fix }} \mathrm{W}_{\text {fix }}\right)$ and (b) the perturbed and control simulations $\left(4 \times \mathrm{CO}_{2}\right.$ minus $\left.1 \times \mathrm{CO}_{2}\right)$. The total (black lines), SW cloud (blue lines), LW cloud (magenta lines), and water vapor feedbacks (cyan lines) are shown. The feedbacks are calculated using the radiative kernel technique (e.g., Soden et al. 2008), with the kernels computed using an aquaplanet version of the GFDL AM2.1 model (Feldl et al. 2017). The seasonal cycle feedbacks in (a) have been normalized by the globalmean SST change between the $\mathrm{S}_{\mathrm{var}} \mathrm{L}_{\mathrm{war}} \mathrm{W}_{\mathrm{var}}$ and $\mathrm{S}_{\mathrm{fix}} \mathrm{L}_{\mathrm{fix}} \mathrm{W}_{\text {fix }}$ simulations, and the feedbacks in (b) have been normalized by the SST change between the C4S4L4W4 and C1S1L1W1 simulations.

additional emergent constraint on monsoons in a changing climate that deserves further investigation. In particular, emergent constraints are deemed to be credible and useful for narrowing uncertainty only if supported by plausible physical mechanisms (Klein and Hall 2015). Whether the equal sensitivities of the axisymmetric monsoon to LW cloud feedbacks over the seasonal cycle and under climate change are indicative of a common underlying mechanism or whether it is a coincidence is an open question. Due to surface hydrology, stationary waves, and other processes, the effects of water vapor and clouds on monsoons are likely to differ substantially between axisymmetric aquaplanet simulations and full-complexity models. This implies that emergent constraints derived in an axisymmetric framework need to be tested extensively in more comprehensive models before their potential applicability to monsoon projections can be fully assessed.
TABLE 3. Sensitivities of precipitation minus evaporation averaged over the axisymmetric monsoon region to temperature-driven water vapor and clouds feedbacks over the seasonal cycle and under climate change. The feedbacks have been calculated using radiative kernels and multiplied by the total global-mean SST changes for the seasonal cycle $\left(\mathrm{S}_{\mathrm{var}} \mathrm{L}_{\mathrm{var}} \mathrm{W}_{\mathrm{var}}\right.$ minus $\left.\mathrm{S}_{\mathrm{fix}} \mathrm{L}_{\mathrm{fix}} \mathrm{W}_{\text {fix }}\right)$ and climate change simulations (C4S4L4W4 minus C1S1L1W1).

\begin{tabular}{lcc}
\hline \hline Sensitivity to & $\begin{array}{c}\text { Seasonal }\left[\mathrm{mm} \mathrm{day}^{-1}\right. \\
\left.\left(\mathrm{W} \mathrm{m}^{-2}\right)^{-1}\right]\end{array}$ & $\begin{array}{c}\text { Climate change }\left[\mathrm{mm} \mathrm{day}^{-1}\right. \\
\left.\left(\mathrm{W} \mathrm{m}^{-2}\right)^{-1}\right]\end{array}$ \\
\hline Water vapor & 0.089 & 0.031 \\
Clouds (LW) & -0.017 & -0.017 \\
Clouds (SW) & -0.016 & 0.000 \\
\hline
\end{tabular}

\section{Summary}

Aerosols affect monsoons (e.g., Bollasina et al. 2011) yet the impacts of other radiatively active atmospheric constituents are relatively unknown. Using a unique collection of radiation-locking simulations performed on an aquaplanet, the influences of clouds, water vapor, and $\mathrm{CO}_{2}$ on an axisymmetric monsoon have been investigated. For the climatological monsoon, the combined effect of seasonally varying clouds and water vapor is to reduce net monsoon precipitation by more than $40 \%$. This drying of the axisymmetric monsoon by seasonal radiative feedbacks is driven primarily by the SW effect of clouds, which substantially reduces incoming TOA radiation, cooling the monsoon region and weakening the divergent circulation. The LW greenhouse effects of seasonally varying clouds and water vapor counteract the SW drying to some extent by invigorating ascent and moistening the core of the axisymmetric monsoon. Seasonal cloud and water vapor feedbacks also widen the axisymmetric monsoon region and shift the location of peak net monsoon precipitation marginally equatorward. These individual moist-radiative feedbacks can also shift the date of axisymmetric monsoon onset by up to approximately two weeks. A conceptual model is developed relating changes in axisymmetric monsoon onset to the efficiency of surface cooling; future research could further develop and potentially apply this framework to identify the physical origins of biases in monsoon onset in weather and climate models.

The radiative effects of clouds, water vapor, and $\mathrm{CO}_{2}$ all strongly influence the axisymmetric monsoon response to an abrupt $\mathrm{CO}_{2}$ quadrupling. $\mathrm{CO}_{2}$ forcing and the water vapor feedback affect the axisymmetric monsoon in similar ways: Both tend to strengthen net precipitation, modestly narrow the monsoon region, and move the monsoon equatorward. The effects of $\mathrm{CO}_{2}$ and water vapor on the axisymmetric monsoon response to climate change are primarily thermodynamic: As greenhouse gases, both warm the monsoon region, increase specific humidity, and broadly moisten 
the axisymmetric monsoon. In contrast, the large impacts of SW and LW cloud feedbacks on the axisymmetric monsoon response are predominantly dynamic in nature. Despite having a negligible influence on SSTs in the monsoon region, cloud feedbacks perturb TOA energy fluxes and induce dipole-like changes in the axisymmetric monsoon circulation. The SW cloud feedback strengthens ascent on the poleward side of the axisymmetric monsoon and weakens ascent on the equatorward side; circulation changes driven by the LW cloud feedback are the mirror image of the SW changes. Leveraging the strong coupling between clouds and circulation, the influence of the LW cloud feedback on the axisymmetric monsoon circulation is estimated as a function of the feedback itself and the climatological relationship between cloud radiative effect and vertical velocity. By linking the climate change response of the axisymmetric monsoon circulation to a climatological relationship in the model, this analysis has revealed a potential emergent constraint on monsoons that will be investigated in future work. Similar sensitivities of the axisymmetric monsoon to LW cloud feedbacks over the seasonal cycle and under climate change are also found, suggesting that the seasonal behavior of the monsoon could be a useful analog for the climate change response.

This study has highlighted the leading-order roles of clouds and water vapor in controlling an axisymmetric monsoon and its response to climate change. The simulations and analyses constitute an advance in our understanding of axisymmetric monsoon dynamics and motivate a variety of new research questions. First, it is essential to quantify the radiative effects of clouds, water vapor, and $\mathrm{CO}_{2}$ on monsoons in full-complexity models. The magnitudes and spatial structures of monsoon-radiation coupling presented in this idealized modeling study are likely to differ substantially from monsoon behavior in the real world and in fullcomplexity models. But if the influence of radiative processes on monsoons is found to be comparable in axisymmetric and full-complexity models, a pressing question is the degree to which the large intermodel spread in monsoon projections is driven by uncertainties in cloud and water vapor feedbacks. Furthermore, results from the idealized simulations presented here suggest observed changes in monsoons over the historical period are likely to have been shaped by cloud and water vapor feedbacks, yet the magnitudes of these effects are unknown. Tropical circulations are affected by patterns of SST and atmospheric heating (Sobel 2007; Harrop and Hartmann 2016), yet the relative influences of these surface versus atmospheric pathways in controlling monsoons are not well understood.
An additional suite of fixed-SST simulations-analogous to runs used to separate the effects of direct radiative forcing versus indirect SST changes on circulation (Shaw and Voigt 2015) - would allow for the effects of SST versus atmospheric heating to be cleanly decomposed, offering new insights into the mechanisms by which clouds and water vapor shape monsoons. Finally, cloud feedbacks are partly controlled by small-scale atmospheric processes that are imperfectly parameterized in global climate models (e.g., Schneider et al. 2017). The extent to which coupling between clouds and monsoons depends on model resolution and parameterizations is an important topic for future research.

Acknowledgments. This project has received funding from the European Union's Horizon 2020 research and innovation programme under the Marie SkłodowskaCurie Grant Agreement 794063 and the UK Natural Environment Research Council's Grant NE/R000727/ 1. MPB thanks Simona Bordoni, Nicole Feldl, Chris O'Reilly, Angeline Pendergrass, Brian Rose, Tiffany Shaw, Marty Singh, and Mark Zelinka for helpful discussions. The Editor (Isaac Held), Aaron Donohoe, Ruth Geen, and an anonymous reviewer are also thanked for their detailed and insightful comments that improved the manuscript. This work used the ARCHER U.K. National Supercomputing Service (http://www. archer.ac.uk).

\section{APPENDIX}

\section{Decomposition of the Effects of Clouds, Water Vapor, and $\mathrm{CO}_{2}$ on an Axisymmetric Monsoon}

\section{a. Seasonal cycle}

Data from the simulations listed in Table 1 are combined to quantify the radiative influences of clouds (SW and $\mathrm{LW}$ ) and water vapor on a given variable $X$, where $X$ is a function of SW cloud properties (S), LW cloud properties (L), and water vapor (W). The total response of $X$ to seasonally varying clouds and water vapor is given by the difference in $X$ between the simulation with seasonally varying clouds and water vapor $\left(\mathrm{S}_{\mathrm{var}} \mathrm{L}_{\mathrm{var}} \mathrm{W}_{\mathrm{var}}\right)$ and the simulation with cloud and water vapor profiles locked to their annual-mean profiles $\left(\mathrm{S}_{\mathrm{fix}} \mathrm{L}_{\mathrm{fix}} \mathrm{W}_{\text {fix }}\right)$ :

$$
\delta X=X_{\mathrm{S}_{\text {var }} \mathrm{L}_{\text {var }} \mathrm{W}_{\text {var }}}-X_{\mathrm{S}_{\text {fix }} \mathrm{L}_{\text {fix }} \mathrm{W}_{\text {fix }}} .
$$

In (A1), the subscript "var" indicates that the quantity varies seasonally in the radiation code and "fix" indicates that the quantity is locked to its annual-mean profile. Following Ceppi and Hartmann (2016) and 
Voigt and Shaw (2015), the cloud and water vapor components of the total response $(\delta X)$ are estimated by taking averages of differences between pairs of locked simulations. The total response is decomposed into SW cloud $\left(\delta X_{\mathrm{S}}\right)$, LW cloud $\left(\delta X_{\mathrm{L}}\right)$, and water vapor components $\left(\delta X_{\mathrm{W}}\right)$ [see $\left.(\mathrm{A} 2)-(\mathrm{A} 4)\right]$, along with a residual component $\left(\delta X_{\text {res }}\right)$ [see (A5)]. The residual component represents the contribution of nonlinear interactions between clouds, water vapor and radiation to the total monsoon response [note that Ceppi and Hartmann (2016) and Voigt and Shaw (2015) absorb the residual into other components in their decompositions]. The residual would be zero if the radiative effects of clouds and water vapor were completely independent from one another. The components are defined below such that their sum equals the total response:

$$
\begin{aligned}
& \delta X_{\mathrm{S}}=\frac{1}{4}\left[\left(X_{\mathrm{S}_{\text {var }} \mathrm{L}_{\text {fix }} \mathrm{W}_{\text {fix }}}+X_{\mathrm{S}_{\text {var }} \mathrm{L}_{\text {fix }} \mathrm{W}_{\text {var }}}+X_{\mathrm{S}_{\text {var }} \mathrm{L}_{\text {var }} \mathrm{W}_{\text {fix }}}+X_{\mathrm{S}_{\text {var }} \mathrm{L}_{\text {var }} \mathrm{W}_{\text {var }}}\right)\right. \\
& \left.-\left(X_{\mathrm{S}_{\text {fix }} \mathrm{L}_{\text {fix }} \mathrm{w}_{\text {fix }}}+X_{\mathrm{S}_{\text {fix }} \mathrm{L}_{\text {fix }} \mathrm{W}_{\text {var }}}+X_{\mathrm{S}_{\text {fix }} \mathrm{L}_{\text {var }} \mathrm{W}_{\text {fix }}}+X_{\mathrm{S}_{\text {fix }} \mathrm{L}_{\text {var }} \mathrm{W}_{\text {var }}}\right)\right], \\
& \delta X_{\mathrm{L}}=\frac{1}{4}\left[\left(X_{\mathrm{S}_{\text {fix }} \mathrm{L}_{\text {var }} \mathrm{W}_{\text {fix }}}+X_{\mathrm{S}_{\text {fix }} \mathrm{L}_{\text {var }} \mathrm{W}_{\text {var }}}+X_{\mathrm{S}_{\text {var }} \mathrm{L}_{\text {var }} \mathrm{W}_{\text {fix }}}+X_{\mathrm{S}_{\text {var }} \mathrm{L}_{\text {var }} \mathrm{W}_{\text {var }}}\right)\right. \\
& \left.-\left(X_{\mathrm{S}_{\text {fix }} \mathrm{L}_{\text {fix }} \mathrm{w}_{\text {fix }}}+X_{\mathrm{S}_{\text {fix }} \mathrm{L}_{\text {fix }} \mathrm{w}_{\text {var }}}+X_{\mathrm{S}_{\text {var }} \mathrm{L}_{\text {fix }} \mathrm{W}_{\text {fix }}}+X_{\mathrm{S}_{\text {var }} \mathrm{L}_{\text {fix }} \mathrm{w}_{\text {var }}}\right)\right], \\
& \delta X_{\mathrm{W}}=\frac{1}{4}\left[\left(X_{\mathrm{S}_{\text {fix }} \mathrm{L}_{\text {fix }} \mathrm{W}_{\mathrm{var}}}+X_{\mathrm{S}_{\mathrm{fix}} \mathrm{L}_{\mathrm{var}} \mathrm{W}_{\mathrm{var}}}+X_{\mathrm{S}_{\mathrm{var}} \mathrm{L}_{\mathrm{fix}} \mathrm{W}_{\mathrm{var}}}+X_{\mathrm{S}_{\mathrm{var}} \mathrm{L}_{\text {var }} \mathrm{W}_{\mathrm{var}}}\right)\right. \\
& \left.-\left(X_{\mathrm{S}_{\text {fix }} \mathrm{L}_{\text {fix }} \mathrm{W}_{\text {fix }}}+X_{\mathrm{S}_{\text {fix }} \mathrm{L}_{\text {var }} \mathrm{w}_{\text {fix }}}+X_{\mathrm{S}_{\text {var }} \mathrm{L}_{\text {fix }} \mathrm{W}_{\text {fix }}}+X_{\mathrm{S}_{\text {var }} \mathrm{L}_{\text {var }} \mathrm{w}_{\text {fix }}}\right)\right],
\end{aligned}
$$

$$
\begin{aligned}
\delta X_{\text {res }}= & \frac{1}{4}\left[\left(X_{\mathrm{S}_{\text {var }} \mathrm{L}_{\text {var }} \mathrm{W}_{\text {var }}}+X_{\mathrm{S}_{\text {fix }} \mathrm{L}_{\text {fix }} \mathrm{W}_{\text {var }}}+X_{\mathrm{S}_{\text {fix }} \mathrm{L}_{\text {var }} \mathrm{W}_{\text {fix }}}+X_{\mathrm{S}_{\text {var }} \mathrm{L}_{\text {fix }} \mathrm{w}_{\text {fix }}}\right)\right. \\
& \left.-\left(X_{\mathrm{S}_{\text {fix }} \mathrm{L}_{\text {var }} \mathrm{W}_{\text {var }}}+X_{\mathrm{S}_{\text {var }} \mathrm{L}_{\text {fix }} \mathrm{W}_{\text {var }}}+X_{\mathrm{S}_{\text {fix }} \mathrm{L}_{\text {fix }} \mathrm{W}_{\text {fix }}}+X_{\mathrm{S}_{\text {var }} \mathrm{L}_{\text {var }} \mathrm{W}_{\text {fix }}}\right)\right] .
\end{aligned}
$$

\section{b. Climate change}

Using the radiation-locking simulations listed in Table 2, the radiative influences of $\mathrm{CO}_{2}$, clouds, and water vapor on the axisymmetric monsoon response to climate change are decomposed. The total response of a variable $X$ to an abrupt quadrupling of $\mathrm{CO}_{2}$, including cloud and water vapor feedbacks, is given by the difference between the C4S4L4W4 and C1S1L1W1 simulations:

$$
\delta X=X_{\mathrm{C} 4 \mathrm{~S} 4 \mathrm{~L} 4 \mathrm{~W} 4}-X_{\mathrm{C} 1 \mathrm{~S} 1 \mathrm{~L} 1 \mathrm{~W} 1},
$$

where "C" denotes the $\mathrm{CO}_{2}$ concentration, "S" the $\mathrm{SW}$ cloud properties, "L" the LW cloud properties, and "W" water vapor; " 1 " indicates that the property is locked to its values in the control simulation $\left(1 \times \mathrm{CO}_{2}\right)$, and " 4 " indicates that it is locked to its values in the perturbed simulation $\left(4 \times \mathrm{CO}_{2}\right)$. The $\mathrm{CO}_{2}\left(\delta X_{\mathrm{C}}\right)$, SW cloud $\left(\delta X_{\mathrm{S}}\right)$, LW cloud $\left(\delta X_{\mathrm{L}}\right)$, and water vapor components $\left(\delta X_{\mathrm{W}}\right)$ of the total response are defined in Eqs. (A7)-(A10) below as averages of differences between pairs of locked simulations. The residual component ( $\left.\delta X_{\text {res }}\right)$, which quantifies the influence of nonlinear interactions between $\mathrm{CO}_{2}$, clouds, and water vapor on the monsoon response, is also defined below [(A11)]:

$$
\begin{aligned}
& \delta X_{\mathrm{C}}=\frac{1}{8}\left(X_{\mathrm{C} 4 \mathrm{~S} 1 \mathrm{~L} 1 \mathrm{~W} 1}+X_{\mathrm{C} 4 \mathrm{~S} 4 \mathrm{~L} 1 \mathrm{~W} 1}+X_{\mathrm{C} 4 \mathrm{~S} 1 \mathrm{~L} 4 \mathrm{~W} 1}+X_{\mathrm{C} 4 \mathrm{~S} 1 \mathrm{~L} 1 \mathrm{~W} 4}+X_{\mathrm{C} 4 \mathrm{~S} 4 \mathrm{~L} 4 \mathrm{~W} 1}+X_{\mathrm{C} 4 \mathrm{~S} 4 \mathrm{~L} 1 \mathrm{~W} 4}+X_{\mathrm{C} 4 \mathrm{~S} 1 \mathrm{~L} 4 \mathrm{~W} 4}+X_{\mathrm{C} 454 \mathrm{~L} 4 \mathrm{~W} 4}\right) \\
& -\left(X_{\mathrm{C} 1 \mathrm{~S} 1 \mathrm{~L} 1 \mathrm{~W} 1}+X_{\mathrm{C} 1 \mathrm{~S} 4 \mathrm{~L} 1 \mathrm{~W} 1}+X_{\mathrm{C} 1 \mathrm{~S} 1 \mathrm{~L} 4 \mathrm{~W} 1}+X_{\mathrm{C} 1 \mathrm{~S} 1 \mathrm{~L} 1 \mathrm{~W} 4}+X_{\mathrm{C} 1 \mathrm{~S} 4 \mathrm{~L} 4 \mathrm{~W} 1}+X_{\mathrm{C} 154 \mathrm{~L} 1 \mathrm{~W} 4}+X_{\mathrm{C} 1 \mathrm{~S} 1 \mathrm{~L} 4 \mathrm{~W} 4}+X_{\mathrm{C} 154 \mathrm{~L} 4 \mathrm{~W} 4}\right) \text {, } \\
& \delta X_{\mathrm{S}}=\frac{1}{8}\left(X_{\mathrm{C} 1 \mathrm{~S} 4 \mathrm{~L} 1 \mathrm{~W} 1}+X_{\mathrm{C} 1 \mathrm{~S} 4 \mathrm{~L} 4 \mathrm{~W} 1}+X_{\mathrm{C} 1 \mathrm{~S} 4 \mathrm{~L} 1 \mathrm{~W} 4}+X_{\mathrm{C} 1 \mathrm{~S} 4 \mathrm{~L} 4 \mathrm{~W} 4}+X_{\mathrm{C} 4 \mathrm{~S} 4 \mathrm{~L} 1 \mathrm{~W} 1}+X_{\mathrm{C} 4 \mathrm{~S} 4 \mathrm{~L} 4 \mathrm{~W} 1}+X_{\mathrm{C} 4 \mathrm{~S} 4 \mathrm{~L} 1 \mathrm{~W} 4}+X_{\mathrm{C} 4 \mathrm{~S} 4 \mathrm{~L} 4 \mathrm{~W} 4}\right) \\
& -\left(X_{\mathrm{C} 1 \mathrm{~S} 1 \mathrm{~L} 1 \mathrm{~W} 1}+X_{\mathrm{C} 1 \mathrm{~S} 1 \mathrm{~L} 4 \mathrm{~W} 1}+X_{\mathrm{C} 1 \mathrm{~S} 1 \mathrm{~L} 1 \mathrm{~W} 4}+X_{\mathrm{C} 1 \mathrm{~S} 1 \mathrm{~L} 4 \mathrm{~W} 4}+X_{\mathrm{C} 4 \mathrm{~S} 1 \mathrm{~L} 1 \mathrm{~W} 1}+X_{\mathrm{C} 4 \mathrm{~S} 1 \mathrm{~L} 4 \mathrm{~W} 1}+X_{\mathrm{C} 4 \mathrm{~L} 1 \mathrm{~L} 1 \mathrm{~W} 4}+X_{\mathrm{C} 4 \mathrm{~S} 1 \mathrm{~L} 4 \mathrm{~W} 4}\right), \\
& \delta X_{\mathrm{L}}=\frac{1}{8}\left(X_{\mathrm{C} 1 \mathrm{~S} 1 \mathrm{~L} 4 \mathrm{~W} 1}+X_{\mathrm{C} 1 \mathrm{~S} 4 \mathrm{~L} 4 \mathrm{~W} 1}+X_{\mathrm{C} 1 \mathrm{~S} 1 \mathrm{~L} 4 \mathrm{~W} 4}+X_{\mathrm{C} 1 \mathrm{~S} 4 \mathrm{~L} 4 \mathrm{~W} 4}+X_{\mathrm{C} 4 \mathrm{~S} 1 \mathrm{~L} 4 \mathrm{~W} 1}+X_{\mathrm{C} 4 \mathrm{~S} 4 \mathrm{~L} 4 \mathrm{~W} 1}+X_{\mathrm{C} 4 \mathrm{~S} 1 \mathrm{~L} 4 \mathrm{~W} 4}+X_{\mathrm{C} 4 \mathrm{~S} 4 \mathrm{~L} 4 \mathrm{~W} 4}\right) \\
& -\left(X_{\mathrm{C} 1 \mathrm{~S} 1 \mathrm{~L} 1 \mathrm{w} 1}+X_{\mathrm{C} 1 \mathrm{~S} 4 \mathrm{~L} 1 \mathrm{~W} 1}+X_{\mathrm{C} 1 \mathrm{~L} 1 \mathrm{~L} 1 \mathrm{~W} 4}+X_{\mathrm{C} 1 \mathrm{~S} 4 \mathrm{~L} 1 \mathrm{~W} 4}+X_{\mathrm{C} 4 \mathrm{~S} 1 \mathrm{~L} 1 \mathrm{~W} 1}+X_{\mathrm{C} 4 \mathrm{~S} 4 \mathrm{~L} 1 \mathrm{~W} 1}+X_{\mathrm{C} 4 \mathrm{~S} 1 \mathrm{~L} 1 \mathrm{~W} 4}+X_{\mathrm{C} 454 \mathrm{~L} 1 \mathrm{~W} 4}\right) \text {, }
\end{aligned}
$$




$$
\begin{aligned}
\delta X_{\mathrm{W}}= & \frac{1}{8}\left(X_{\mathrm{C} 1 \mathrm{~S} 1 \mathrm{~L} 1 \mathrm{~W} 4}+X_{\mathrm{C} 1 \mathrm{~S} 4 \mathrm{~L} 1 \mathrm{~W} 4}+X_{\mathrm{C} 1 \mathrm{~S} 1 \mathrm{~L} 4 \mathrm{~W} 4}+X_{\mathrm{C} 1 \mathrm{~S} 4 \mathrm{~L} 4 \mathrm{~W} 4}+X_{\mathrm{C} 4 \mathrm{~S} 1 \mathrm{~L} 1 \mathrm{~W} 4}+X_{\mathrm{C} 4 \mathrm{~S} 4 \mathrm{~L} 1 \mathrm{~W} 4}+X_{\mathrm{C} 4 \mathrm{~S} 1 \mathrm{~L} 4 \mathrm{~W} 4}+X_{\mathrm{C} 4 \mathrm{~S} 4 \mathrm{~L} 4 \mathrm{~W} 4}\right) \\
& -\left(X_{\mathrm{C} 1 \mathrm{~S} 1 \mathrm{~L} 1 \mathrm{~W} 1}+X_{\mathrm{C} 1 \mathrm{~S} 4 \mathrm{~L} 1 \mathrm{~W} 1}+X_{\mathrm{C} 1 \mathrm{~S} 1 \mathrm{~L} 4 \mathrm{~W} 1}+X_{\mathrm{C} 1 \mathrm{~S} 4 \mathrm{~L} 4 \mathrm{~W} 1}+X_{\mathrm{C} 4 \mathrm{~S} 1 \mathrm{~L} 1 \mathrm{~W} 1}+X_{\mathrm{C} 4 \mathrm{~S} 4 \mathrm{~L} 1 \mathrm{~W} 1}+X_{\mathrm{C} 4 \mathrm{~S} 1 \mathrm{~L} 4 \mathrm{~W} 1}+X_{\mathrm{C} 4 \mathrm{~S} 4 \mathrm{~L} 4 \mathrm{~W} 1}\right)
\end{aligned}
$$

$$
\begin{aligned}
\delta X_{\mathrm{res}}= & \frac{1}{4}\left(2 \times X_{\mathrm{C} 4 \mathrm{~S} 4 \mathrm{~L} 4 \mathrm{~W} 4}+X_{\mathrm{C} 4 \mathrm{~S} 1 \mathrm{~L} 1 \mathrm{~W} 1}+X_{\mathrm{C} 1 \mathrm{~S} 1 \mathrm{~L} 1 \mathrm{~W} 4}+X_{\mathrm{C} 1 \mathrm{~S} 4 \mathrm{~L} 1 \mathrm{~W} 1}+X_{\mathrm{C} 1 \mathrm{~S} 1 \mathrm{~L} 4 \mathrm{~W} 1}\right) \\
& -\left(2 \times X_{\mathrm{C} 1 \mathrm{~S} 1 \mathrm{~L} 1 \mathrm{~W} 1}+X_{\mathrm{C} 1 \mathrm{~S} 4 \mathrm{~L} 4 \mathrm{~W} 4}+X_{\mathrm{C} 4 \mathrm{~S} 4 \mathrm{~L} 4 \mathrm{~W} 1}+X_{\mathrm{C} 4 \mathrm{~S} 4 \mathrm{~L} 1 \mathrm{~W} 4}+X_{\mathrm{C} 4 \mathrm{~S} 1 \mathrm{~L} 4 \mathrm{~W} 4}\right) .
\end{aligned}
$$

The sum of the $\mathrm{CO}_{2}$, cloud, water vapor, and residual components defined by (A7)-(A11) exactly equals the total response $(\delta X)$.

\section{REFERENCES}

Ackerman, S. A., and S. K. Cox, 1987: Radiative energy budget estimates for the 1979 southwest summer monsoon. J. Atmos. Sci., 44, 3052-3078, https://doi.org/10.1175/1520-0469(1987) 044<3052:REBEFT>2.0.CO;2.

Adam, O., T. Bischoff, and T. Schneider, 2016: Seasonal and interannual variations of the energy flux equator and ITCZ. Part I: Zonally averaged ITCZ position. J. Climate, 29, 3219-3230, https://doi.org/10.1175/JCLI-D-15-0512.1.

Allan, R. P., 2011: Combining satellite data and models to estimate cloud radiative effect at the surface and in the atmosphere. Meteor. Appl., 18, 324-333, https://doi.org/10.1002/met.285.

Andrews, T., J. M. Gregory, M. J. Webb, and K. E. Taylor, 2012: Forcing, feedbacks and climate sensitivity in CMIP5 coupled atmosphere-ocean climate models. Geophys. Res. Lett., 39, L09712, https://doi.org/10.1029/2012GL051607.

Back, L. E., and C. S. Bretherton, 2009: On the relationship between SST gradients, boundary layer winds, and convergence over the tropical oceans. J. Climate, 22, 4182-4196, https:// doi.org/10.1175/2009JCLI2392.1.

Bischoff, T., and T. Schneider, 2014: Energetic constraints on the position of the intertropical convergence zone. J. Climate, 27, 4937-4951, https://doi.org/10.1175/JCLI-D-13-00650.1.

Bollasina, M. A., Y. Ming, and V. Ramaswamy, 2011: Anthropogenic aerosols and the weakening of the South Asian summer monsoon. Science, 334, 502-505, https://doi.org/10.1126/science.1204994.

Bony, S., and K. A. Emanuel, 2005: On the role of moist processes in tropical intraseasonal variability: Cloud-radiation and moisture-convection feedbacks. J. Atmos. Sci., 62, 2770-2789, https://doi.org/10.1175/JAS3506.1.

- J J.-L. Dufresne, H. Le Treut, J.-J. Morcrette, and C. Senior, 2004: On dynamic and thermodynamic components of cloud changes. Climate Dyn., 22, 71-86, https://doi.org/10.1007/ s00382-003-0369-6.

- M. Webb, C. Bretherton, S. A. Klein, P. Siebesma, G. Tselioudis, and M. Zhang, 2011: CFMIP: Towards a better evaluation and understanding of clouds and cloud feedbacks in CMIP5 models. CLIVAR Exchanges, No. 56, International CLIVAR Project Office, Southampton, United Kingdom, 20-22.

Boos, W. R., 2012: Thermodynamic scaling of the hydrological cycle of the Last Glacial Maximum. J. Climate, 25, 992-1006, https://doi.org/10.1175/JCLI-D-11-00010.1.

—_, and K. A. Emanuel, 2008: Wind-evaporation feedback and abrupt seasonal transitions of weak, axisymmetric Hadley circulations. J. Atmos. Sci., 65, 2194-2214, https://doi.org/ 10.1175/2007JAS2608.1.

— and - 2009: Annual intensification of the Somali jet in a quasi-equilibrium framework: Observational composites. Quart. J. Roy. Meteor. Soc., 135, 319-335, https://doi.org/ 10.1002/qj.388.

Bordoni, S., and T. Schneider, 2008: Monsoons as eddy-mediated regime transitions of the tropical overturning circulation. Nat. Geosci., 1, 515-519, https://doi.org/10.1038/ngeo248.

Byrne, M. P., and P. A. O'Gorman, 2015: The response of precipitation minus evapotranspiration to climate warming: Why the "wet-get-wetter, dry-get-drier" scaling does not hold over land. J. Climate, 28, 8078-8092, https://doi.org/10.1175/JCLID-15-0369.1.

_ , and T. Schneider, 2016: Energetic constraints on the width of the intertropical convergence zone. J. Climate, 29, 4709-4721, https://doi.org/10.1175/JCLI-D-15-0767.1.

$\longrightarrow$, and - 2018: Atmospheric dynamics feedback: Concept, simulations and climate implications. J. Climate, 31, 32493264, https://doi.org/10.1175/JCLI-D-17-0470.1.

Ceppi, P., and D. L. Hartmann, 2016: Clouds and the atmospheric circulation response to warming. J. Climate, 29, 783-799, https://doi.org/10.1175/JCLI-D-15-0394.1.

— , F. Brient, M. D. Zelinka, and D. L. Hartmann, 2017: Cloud feedback mechanisms and their representation in global climate models. Wiley Interdiscip. Rev.: Climate Change, 8, e465, https://doi.org/10.1002/WCC.465.

Chao, W. C., 2000: Multiple quasi equilibria of the ITCZ and the origin of monsoon onset. J. Atmos. Sci., 57, 641-652, https://doi.org/ 10.1175/1520-0469(2000)057<0641:MQEOTI>2.0.CO;2.

Chou, C., and J. D. Neelin, 2004: Mechanisms of global warming impacts on regional tropical precipitation. J. Climate, 17, 2688-2701, https://doi.org/10.1175/1520-0442(2004)017<2688: MOGWIO $>2.0 . \mathrm{CO} ; 2$.

,-- C.-A. Chen, and J.-Y. Tu, 2009: Evaluating the "richget-richer" mechanism in tropical precipitation change under global warming. J. Climate, 22, 1982-2005, https://doi.org/ 10.1175/2008JCLI2471.1.

Clark, S. K., Y. Ming, I. M. Held, and P. J. Phillipps, 2018: The role of the water vapor feedback in the ITCZ response to hemispherically asymmetric forcings. J. Climate, 31, 3659-3678, https://doi.org/10.1175/JCLI-D-17-0723.1.

Dessler, A. E., Z. Zhang, and P. Yang, 2008: Water-vapor climate feedback inferred from climate fluctuations, 20032008. Geophys. Res. Lett., 35, L20704, https://doi.org/10.1029/ 2008GL035333.

Dong, B., L. J. Wilcox, E. J. Highwood, and R. T. Sutton, 2019: Impacts of recent decadal changes in Asian aerosols on the East Asian summer monsoon: Roles of aerosol-radiation and aerosol-cloud interactions. Climate Dyn., 53, 3235-3256, https:// doi.org/10.1007/s00382-019-04698-0. 
Donohoe, A., and D. S. Battisti, 2013: The seasonal cycle of atmospheric heating and temperature. J. Climate, 26, 4962-4980, https://doi.org/10.1175/JCLI-D-12-00713.1.

- D. M. W. Frierson, and D. S. Battisti, 2014: The effect of ocean mixed layer depth on climate in slab ocean aquaplanet experiments. Climate Dyn., 43, 1041-1055, https://doi.org/ 10.1007/s00382-013-1843-4.

Duffy, M. L., P. A. O'Gorman, and L. E. Back, 2020: Importance of Laplacian of low-level warming for the response of precipitation to climate change over tropical oceans. J. Climate, $\mathbf{3 3}$, 4403-4417, https://doi.org/10.1175/JCLI-D-19-0365.1.

Emanuel, K. A., 1995: On thermally direct circulations in moist atmospheres. J. Atmos. Sci., 52, 1529-1536, https://doi.org/ 10.1175/1520-0469(1995)052<1529:OTDCIM>2.0.CO;2.

Feldl, N., S. Bordoni, and T. M. Merlis, 2017: Coupled high-latitude climate feedbacks and their impact on atmospheric heat transport. J. Climate, 30, 189-201, https://doi.org/10.1175/ JCLI-D-16-0324.1.

Frierson, D. M. W., and Y.-T. Hwang, 2012: Extratropical influence on ITCZ shifts in slab ocean simulations of global warming. J. Climate, 25, 720-733, https://doi.org/10.1175/JCLI-D-11-00116.1.

Gadgil, S., 2018: The monsoon system: Land-sea breeze or the ITCZ? J. Earth Syst. Sci., 127, 1, https://doi.org/10.1007/ s12040-017-0916-x.

Geen, R., F. H. Lambert, and G. K. Vallis, 2019: Processes and timescales in onset and withdrawal of "aquaplanet monsoons." J. Atmos. Sci., 76, 2357-2373, https://doi.org/10.1175/ JAS-D-18-0214.1.

Guo, Z., T. Zhou, M. Wang, and Y. Qian, 2015: Impact of cloud radiative heating on East Asian summer monsoon circulation. Environ. Res. Lett., 10, 074014, https://doi.org/10.1088/17489326/10/7/074014.

Hall, A., and S. Manabe, 1999: The role of water vapor feedback in unperturbed climate variability and global warming. J. Climate, 12, 2327-2346, https://doi.org/10.1175/1520-0442(1999)012<2327: TROWVF $>2.0 . \mathrm{CO} ; 2$.

Harrop, B. E., and D. L. Hartmann, 2016: The role of cloud radiative heating within the atmosphere on the high cloud amount and top-of-atmosphere cloud radiative effect. J. Adv. Model. Earth Syst., 8, 1391-1410, https://doi.org/10.1002/2016MS000670.

Held, I. M., and A. Y. Hou, 1980: Nonlinear axially symmetric circulations in a nearly inviscid atmosphere. J. Atmos. Sci., 37, 515-533, https://doi.org/10.1175/1520-0469(1980)037<0515: NASCIA $>2.0 . \mathrm{CO} ; 2$.

- , and B. J. Soden, 2000: Water vapor feedback and global warming. Annu. Rev. Energy Environ., 25, 441-475, https:// doi.org/10.1146/annurev.energy.25.1.441.

- , and - 2006: Robust responses of the hydrological cycle to global warming. J. Climate, 19, 5686-5699, https://doi.org/ 10.1175/JCLI3990.1.

Hill, S. A., 2019: Theories for past and future monsoon rainfall changes. Curr. Climate Change Rep., 5, 160-171, https:// doi.org/10.1007/s40641-019-00137-8.

Hurrell, J. W., and Coauthors, 2013: The Community Earth System Model: A framework for collaborative research. Bull. Amer. Meteor. Soc., 94, 1339-1360, https://doi.org/10.1175/BAMS-D12-00121.1.

Kang, S. M., I. M. Held, D. M. W. Frierson, and M. Zhao, 2008: The response of the ITCZ to extratropical thermal forcing: Idealized slab-ocean experiments with a GCM. J. Climate, 21, 3521-3532, https://doi.org/10.1175/2007JCLI2146.1.

Kitoh, A., H. Endo, K. Krishna Kumar, I. F. A. Cavalcanti, P. Goswami, and T. Zhou, 2013: Monsoons in a changing world:
A regional perspective in a global context. J. Geophys. Res. Atmos., 118, 3053-3065, https://doi.org/10.1002/JGRD.50258.

Klein, S. A., and A. Hall, 2015: Emergent constraints for cloud feedbacks. Curr. Climate Change Rep., 1, 276-287, https:// doi.org/10.1007/s40641-015-0027-1.

,$- \ldots$, J. R. Norris, and R. Pincus, 2017: Low-cloud feedbacks from cloud-controlling factors: A review. Shallow Clouds, Water Vapor, Circulation, and Climate Sensitivity, Springer, 135-157.

Li, J., J. Mao, and F. Wang, 2017: Comparative study of five current reanalyses in characterizing total cloud fraction and top-ofthe-atmosphere cloud radiative effects over the Asian monsoon region. Int. J. Climatol., 37, 5047-5067, https://doi.org/ 10.1002/joc. 5143 .

Lindzen, R. S., and S. Nigam, 1987: On the role of sea surface temperature gradients in forcing low-level winds and convergence in the tropics. J. Atmos. Sci., 44, 2418-2436, https:// doi.org/10.1175/1520-0469(1987)044<2418:OTROSS >2.0. $\mathrm{CO} ; 2$.

, and A. V. Hou, 1988: Hadley circulations for zonally averaged heating centered off the equator. J. Atmos. Sci. 45, 2416-2427, https:// doi.org/10.1175/1520-0469(1988)045<2416:HCFZAH>2.0.CO;2.

Lu, J., G. A. Vecchi, and T. Reichler, 2007: Expansion of the Hadley cell under global warming. Geophys. Res. Lett., 34, L06805, https://doi.org/10.1029/2006GL028443.

MacMynowski, D. G., H.-J. Shin, and K. Caldeira, 2011: The frequency response of temperature and precipitation in a climate model. Geophys. Res. Lett., 38, L16711, https://oi.org/10.1029/ 2011 GL048623.

Merlis, T. M., 2015: Direct weakening of tropical circulations from masked $\mathrm{CO}_{2}$ radiative forcing. Proc. Natl. Acad. Sci. USA, 112, 13 167-13 171, https://doi.org/10.1073/pnas.1508268112.

Mitchell, J. F. B., C. A. Wilson, and W. M. Cunnington, 1987: On $\mathrm{CO}_{2}$ climate sensitivity and model dependence of results. Quart. J. Roy. Meteor. Soc., 113, 293-322, https://doi.org/ 10.1256/smsqj.47516.

Molnar, P., W. R. Boos, and D. S. Battisti, 2010: Orographic controls on climate and paleoclimate of Asia: Thermal and mechanical roles for the Tibetan Plateau. Annu. Rev. Earth Planet. Sci., 38, 77-102, https://doi.org/10.1146/annurev-earth040809-152456.

Neale, R. B., and Coauthors, 2010: Description of the NCAR Community Atmosphere Model (CAM 4.0). NCAR Tech. Note NCAR/TN-485+STR, 212 pp., www.cesm.ucar.edu/ models/ccsm4.0/cam/docs/description/cam4_desc.pdf.

Neelin, J. D., and I. M. Held, 1987: Modeling tropical convergence based on the moist static energy budget. Mon. Wea. Rev., 115, 3-12, https:// doi.org/10.1175/1520-0493(1987)115<0003:MTCBOT>2.0.CO;2.

Nie, J., W. R. Boos, and Z. Kuang, 2010: Observational evaluation of a convective quasi-equilibrium view of monsoons. J. Climate, 23, 4416-4428, https://doi.org/10.1175/2010JCLI3505.1.

Plumb, R. A., and A. Y. Hou, 1992: The response of a zonally symmetric atmosphere to subtropical thermal forcing: Threshold behavior. J. Atmos. Sci., 49, 1790-1799, https://doi.org/10.1175/ 1520-0469(1992)049<1790:TROAZS > 2.0.CO;2.

Privé, N. C., and R. A. Plumb, 2007: Monsoon dynamics with interactive forcing. Part I: Axisymmetric studies. J. Atmos. Sci., 64, 1417-1430, https://doi.org/10.1175/JAS3916.1.

Ramanathan, V. L., R. D. Cess, E. F. Harrison, P. Minnis, B. R. Barkstrom, E. Ahmad, and D. Hartmann, 1989: Cloud-radiative forcing and climate: Results from the Earth Radiation Budget Experiment. Science, 243, 57-63, https://doi.org/ 10.1126/science.243.4887.57. 
Roe, G. H., N. Feldl, K. C. Armour, Y.-T. Hwang, and D. M. W. Frierson, 2015: The remote impacts of climate feedbacks on regional climate predictability. Nat. Geosci., 8, 135-139, https://doi.org/10.1038/ngeo2346.

Schneider, E. K., 1977: Axially symmetric steady-state models of the basic state for instability and climate studies. Part II. Nonlinear calculations. J. Atmos. Sci., 34, 280-296, https://doi.org/10.1175/ 1520-0469(1977)034<0280:ASSSMO > 2.0.CO;2.

Schneider, T., and S. Bordoni, 2008: Eddy-mediated regime transitions in the seasonal cycle of a Hadley circulation and implications for monsoon dynamics. J. Atmos. Sci., 65, 915-934, https://doi.org/10.1175/2007JAS2415.1.

—, J. Teixeira, C. S. Bretherton, F. Brient, K. G. Pressel, C. Schär, and A. P. Siebesma, 2017: Climate goals and computing the future of clouds. Nat. Climate Change, 7, 3-5, https://doi.org/10.1038/nclimate3190.

Seager, R., N. Naik, and G. A. Vecchi, 2010: Thermodynamic and dynamic mechanisms for large-scale changes in the hydrological cycle in response to global warming. J. Climate, $\mathbf{2 3}$, 4651-4668, https://doi.org/10.1175/2010JCLI3655.1.

Seth, A., S. A. Rauscher, M. Biasutti, A. Giannini, S. J. Camargo, and M. Rojas, 2013: CMIP5 projected changes in the annual cycle of precipitation in monsoon regions. J. Climate, 26, 73287351, https://doi.org/10.1175/JCLI-D-12-00726.1.

Shaw, T. A., and A. Voigt, 2015: Tug of war on summertime circulation between radiative forcing and sea surface warming. Nat. Geosci., 8, 560-566, https://doi.org/10.1038/ngeo2449.

__, and _ 2016: Understanding the links between subtropical and extratropical circulation responses to climate change using aquaplanet model simulations. J. Climate, 29, 6637-6657, https://doi.org/10.1175/JCLI-D-16-0049.1.

Shepherd, T. G., 2014: Atmospheric circulation as a source of uncertainty in climate change projections. Nat. Geosci., 7, 703708, https://doi.org/10.1038/ngeo2253.

Sherwood, S. C., S. Bony, and J.-L. Dufresne, 2014: Spread in model climate sensitivity traced to atmospheric convective mixing. Nature, 505, 37-42, https://doi.org/10.1038/nature12829.

Simpson, G. C., 1921: The south-west monsoon. Quart. J. Roy. Meteor Soc., 47, 151-171, https://doi.org/10.1002/qj.49704719901.

Sobel, A. H., 2007: Simple models of ensemble-averaged precipitation and surface wind, given the sea surface temperature. The Global Circulation of the Atmosphere, T. Schneider and A. H. Sobel, Eds., Princeton Press, 219-251.

Soden, B. J., I. M. Held, R. Colman, K. M. Shell, J. T. Kiehl, and C. A. Shields, 2008: Quantifying climate feedbacks using radiative kernels. J. Climate, 21, 3504-3520, https://doi.org/ 10.1175/2007JCLI2110.1.
Stephens, G. L., 2005: Cloud feedbacks in the climate system: A critical review. J. Climate, 18, 237-273, https://doi.org/10.1175/ JCLI-3243.1.

Turner, A. G., and H. Annamalai, 2012: Climate change and the South Asian summer monsoon. Nat. Climate Change, 2, 587595, https://doi.org/10.1038/nclimate1495.

Voigt, A., and T. A. Shaw, 2015: Circulation response to warming shaped by radiative changes of clouds and water vapour. Nat. Geosci., 8, 102-106, https://doi.org/10.1038/ngeo2345.

- B. Stevens, J. Bader, and T. Mauritsen, 2014: Compensation of hemispheric albedo asymmetries by shifts of the ITCZ and tropical clouds. J. Climate, 27, 1029-1045, https://doi.org/ 10.1175/JCLI-D-13-00205.1.

Wang, B., and Q. Ding, 2008: Global monsoon: Dominant mode of annual variation in the tropics. Dyn. Atmos. Oceans, 44, 165183, https://doi.org/10.1016/j.dynatmoce.2007.05.002. and Coauthors, 2020: Monsoons climate change assessment. Bull. Amer. Meteor. Soc., https://doi.org/10.1175/BAMS-D19-0335.1, in press.

Wei, H.-H., and S. Bordoni, 2018: Energetic constraints on the ITCZ position in idealized simulations with a seasonal cycle. J. Adv. Model. Earth Syst., 10, 1708-1725, https://doi.org/ 10.1029/2018MS001313.

Wing, A. A., and K. A. Emanuel, 2014: Physical mechanisms controlling self-aggregation of convection in idealized numerical modeling simulations. J. Adv. Model. Earth Syst., 6, 59-74, https://doi.org/10.1002/2013MS000269.

Wood, R., and C. S. Bretherton, 2006: On the relationship between stratiform low cloud cover and lower-tropospheric stability. J. Climate, 19, 6425-6432, https://doi.org/10.1175/JCLI3988.1.

Wyant, M. C., C. S. Bretherton, J. T. Bacmeister, J. T. Kiehl, I. M. Held, M. Zhao, S. A. Klein, and B. J. Soden, 2006: A comparison of low-latitude cloud properties and their response to climate change in three AGCMs sorted into regimes using mid-tropospheric vertical velocity. Climate Dyn., 27, 261-279, https://doi.org/10.1007/s00382-006-0138-4.

Yano, J.-I., and J. L. McBride, 1998: An aquaplanet monsoon. J. Atmos. Sci., 55, 1373-1399, https://doi.org/10.1175/15200469(1998)055<1373:AAM>2.0.CO;2.

Zelinka, M. D., and D. L. Hartmann, 2012: Climate feedbacks and their implications for poleward energy flux changes in a warming climate. J. Climate, 25, 608-624, https://doi.org/10.1175/JCLI-D-1100096.1.

Zhang, R., S. M. Kang, and I. M. Held, 2010: Sensitivity of climate change induced by the weakening of the Atlantic meridional overturning circulation to cloud feedback. J. Climate, 23, 378389, https://doi.org/10.1175/2009JCLI3118.1. 